\title{
LAS «DOS» CARAS DEL CONSTITUCIONALISMO FRENTE AL PRINCIPIO DE AUTO-DETERMINACIÓN
}

ANTONINO SPADARO 
SUMARIO

1. INTRODUCCIÓN: DEL PRINCIPIO DE AUTO-DETERMINACIÓN «EN ABSTRACTO»A SU APLICACIÓN «PRÁCTICA» EN LOS DISTINTOS ORDENAMIENTOS. 2. ¿AUTO-DETERMINACIÓN O LIBERTAD? ¿CONCEPTOS EQUIVALENTES (SINÓNIMOS) O SOLO SEMEJANTES? 3. LAS DIFERENTES CARAS DE LA AUTO-DETERMINACIÓN EN GENERAL: a) De los pueblos, bajo la forma de $a_{1}$ ) reivindicación interna [autogobierno] y $a_{2}$ ) externa [identidad nacional]... 4. (sigue): $b$ ) De las formaciones sociales: libertad frente al Estado... 5. (sigue): c) Del individuo, bajo la forma de $\mathrm{c}_{1}$ ) otra vez, libertad frente al Estado. La infinidad de las formas de auto-determinación individual y la relación entre subsidiariedad y auto-determinación. La consideración de la CEDH como «control de razonabilidad de II grado». 6. (sigue): $\mathrm{c}_{2}$ ) libertad frente a las mismas formaciones sociales. La auto-determinación individual dentro de las formaciones sociales: sindicatos, partidos, cultos religiosos, familia, etc. 7. RELACIÓN NATURALMENTE DIALÉCTICA - Y EN ALGUNOS CASOS TENSIÓN IRREDUCIBLE_ ENTRE LAS DOS ALMAS FUNDAMENTALES DEL CONSTITUCIONALISMO CONTEMPORÁNEO: «HETEROCÉNTRICA-ALTRUISTA»E «INDIVIDUALISTA-LIBERTARIA». 8. LAS INEVITABLES CONTAMINACIONES ÉTNICO-CULTURALES DE LAS LLAMADAS SOCIEDADES LÍQUIDAS Y LA NECESIDAD DE UN EQUILIBRIO CONSTITUCIONAL, POR MÁS QUE QUEDE IMPERFECTO E IN FIERI. NOTAS DE COMPARACIÓN ENTRE ITALIA Y ESPAÑA. 9. CONCLUSIONES: NECESIDAD DE UNA «JERARQUÍA» DE LAS SITUACIONES JURÍDICAS SUBJETIVAS. «MÁS ALLÁ» DEL INDIVIDUALISMO VOLUNTARISTA («AUTO-DETERMINACIÓN»), HACIA EL PERSONALISMO SOLIDARIO («LIBERTAD DE CONCIENCIA»). 


\title{
LAS «DOS»CARAS DEL CONSTITUCIONALISMO FRENTE AL PRINCIPIO DE AUTO-DETERMINACIÓN*
}

\author{
ANTONINO SPADARO \\ Catedrático de Derecho constitucional, \\ Universidad Mediterránea de Reggio Calabria \\ (spadaro@unirc.it)
}

\section{INTRODUCCIÓN: DEL PRINCIPIO DE AUTO-DETERMINACIÓN «EN ABSTRACTO»A SU APLICACIÓN «PRÁCTICA»EN LOS DISTINTOS ORDENAMIENTOS}

Al analizar el principio de auto-determinación en materia de bioética, cabe preguntarse: ¿por qué en los Países Bajos se permite la eutanasia —el suicidio asistido-y en Grecia no? ¿Por qué en Inglaterra se permite la fecundación asistida a parejas de hecho o mujeres solteras y en Alemania solo a parejas casadas?

Mirando más allá de la bioética, y analizando, por ejemplo, la libertad política, podríamos preguntarnos: ¿por qué la auto-determinación del ciudadano - bajo la forma de derecho a elegir el candidato - es posible en el ordenamiento inglés, en el que hay un mayoritario plurality con circunscripción uninominal, y no es posible en Italia con el sistema electoral llamado porcellum, caracterizado

\footnotetext{
* Ponencia dictada en el VIII Seminario constitucional italo-español sobre La privacidad como autonomía: la doctrina de Estrasburgo y su incidencia en Italia y España, que tuvo lugar en la Universidad de Navarra, Pamplona, el 11 de abril de 2014.
} 
hasta ahora por las listas cerradas? ¿Y por qué el derecho a la representación política —y entonces el principio de auto-determinación del ciudadano a elegir de ser representado por un partido — existe para las fuerzas políticas que superan el 3\% en España y, en cambio, en Turquía, solo para los partidos que superan el $10 \%$ (umbral ante el cual el $8 \%$ para cada partido que no se presenta en coalición previsto por el proyecto del nuevo sistema electoral italiano —llamado italicum- «parece» aceptable)?

Pasando, además, de la bioética y de la libertad política al asunto clásico de la libertad personal, surgen otras preguntas: ¿por qué en algunos países europeos la prostitución está reconocida como una forma de libre auto-determinación (a vender el propio cuerpo), y en otros, en cambio, se sanciona como crimen? ¿Por qué en España los homosexuales pueden casarse y en Italia se espera, como mucho, introducir una disciplina jurídica de las uniones civiles? ¿Por qué es fácil abortar en Suecia y es difícil en Irlanda? ¿Por qué en Turquía el premier Erdogan ha podido — con la desaprobación únicamente del Jefe de Estado Gul y hasta la sentencia de la Corte constitucional- «oscurecer» twitter, y en Francia una operación semejante aparece, desde el punto de vista jurídico, irrealizable, y hasta impensable?

Podríamos seguir — analizando cada libertad distinta o, mejor, cada pretensión de auto-determinación- pero, al final, encontraríamos en cualquier caso, junto a una pequeña parte de disciplina jurídica común, significativas diferencias de tratamiento normativo.

Si estas diferencias (en cuestión de bioética, libertades políticas y civiles, etc.) existen es porque el llamado principio de auto-determinación individual —más allá de su declamación formal y abstracta en los documentos internacionales (a partir del art. 8 de la CEDH y otros) ${ }^{1}$ — está «declinado» de modo profundamente distinto en los varios ordenamientos jurídicos europeos. Los Países del Viejo Continente — aunque todos se reconozcan en la común tradición del constitucionalismo liberaldemocrático y personalista- ofrecen evidentemente soluciones prácticas distintas para los mismos problemas, o (como mucho) soluciones semejantes con matices muy diferentes, porque valoran de manera diferente el Estado, considerándolo en algunas ocasiones «negativo»(injerencia), en otras

${ }^{1}$ Cuyo texto, por comodidad, citamos aquí: «1. Toda persona tiene derecho al respeto de su vida privada y familiar, de su domicilio y de su correspondencia. 2. No podrá haber injerencia de la autoridad pública en el ejercicio de este derecho, sino en tanto en cuanto esta injerencia esté prevista por la ley y constituya una medida que, en una sociedad democrática, sea necesaria para la seguridad nacional, la seguridad pública, el bienestar económico del país, la defensa del orden y la prevención del delito, la protección de la salud o de la moral, o la protección de los derechos y las libertades de los demás». 
«positivo» (protección de otros intereses por lo menos de igual nivel, por ser constitucionalmente protegidos, que hay que «equilibrar» con el de la auto-determinación).

Por lo tanto, la pregunta de las preguntas, o la madre de las demás preguntas, es otra: ¿cómo puede la misma «macro-ideología» del llamado constitucionalismo que funda los ordenamientos constitucionales europeos (el llamado ius publicum europaeum $)^{2}$ — más allá de un mínimo común denominador axiológico, bastante genérico y abstracto, sobre el principio de auto-determinación individual - llevar a resultados «prácticos» tan distintos?

Ante este grundproblem, intentaremos — con dificultad y conscientes de los límites de una investigación en un ámbito tan extenso y complejo — no contestar, sino ofrecer argumentos útiles para una posible respuesta.

Por ahora, diremos solo que la relación de "proporcionalidad automática» entre el nivel de reconocimiento de la auto-determinación individual y el nivel de madurez social y democrática de un sistema jurídico es una simplificación banal y bastante difundida: como veremos, en cambio, más «auto-determinación» no quiere decir siempre y en cualquier caso, más «constitucionalismo». Igualmente, más capacidad de «intervención/injerencia del Estado» no quiere decir necesariamente menor «libertad individual». En fin, hay que evitar fáciles y cómodas generalizaciones.

\section{2. ¿AUTO-DETERMINACIÓN O LIBERTAD? ¿CONCEPTOS EQUIVALENTES (SINÓNIMOS) O SOLO SEMEJANTES?}

Ante todo, hay que decir que, desgraciadamente, el término auto-determinación, igual que muchos otros, está manido por ser muy evocador y por su densidad intrínsecamente sugestiva. A primera vista, podríamos pensar en sustituir simplemente ese término, sin daños, con otra palabra, más imprecisa pero incluso más simple y común: libertad, en realidad igualmente abusada.

El ausente, o reducido, uso del tradicional término «libertad» no depende solo del hecho de que, al igual que las modas en el vestir, de la misma manera existen también las modas lingüísticas —y la palabra «auto-determinación» está de moda - sino que deriva del hecho de que, mientras que la palabra «libertad» es, por así decirlo, tradicional y aparentemente inofensiva, en el término «autodeterminación» se esconde un matiz psicológico de «voluntarismo» que no tiene que sería ingenuo infravalorar. Por consiguiente — en lugar de libertad — se

\footnotetext{
${ }^{2}$ Para la cual, si se quiere, consultar — para algunas primeras indicaciones- mi Costituzionalismo, en Enciclopedia filosofica (Bompiani), vol. III, Milano 2006, 2369 ss.
} 
prefiere a menudo hablar de auto-determinación de los pueblos, de las formaciones sociales y de los individuos.

El ya recordado componente político-voluntarista intrínseco al término «auto-determinación» resulta quizás más compresible, y justificable, en relación al ejercicio «colectivo» de la libertad: para que nos entendamos, es lógico que un pueblo (palestinos, kurdos, etc.) decida librarse del opresor y luchar por la independencia a través de un preciso y costoso acto de auto-determinación. Mucho más complejo y emblemático — por lo menos, así me parece- es el uso del término «auto-determinación» para el ejercicio de una tradicional libertad «individual». En la perspectiva de una concepción del Estado constitucional de tipo liberal, y con más aún razón, en la perspectiva solidaria y personalista, cada libertad individual, en cambio, no es un valor absoluto, sino que tiene siempre un carácter relativo e intrínsecamente relacional, y por lo tanto, paradójicamente, lleva siempre implícita la idea de «límite»33.

Además, mientras que la palabra «libertad» parece meramente descriptiva de un status subjetivo activo que habitualmente llamamos derecho, el término «auto-determinación» individual, en todos sus sentidos, parece indicar más bien el ejercicio de una voluntad precisa e incoercible: allí (en la libertad) se «reconoce» algo, aquí (auto-determinación) como mucho se la re(i)vindica. En fin, la idea de «libertad» evoca un estado de cosas y dentro de ella es implícita, necesariamente, incluso la idea de límite: por principio, las libertades siempre se limitan recíprocamente. En la idea de «auto-determinación» parece — repetimos: parece- que se sobrentiende la necesidad de una acción para defender una condición amenazada, o todavía no (o no plenamente) gozada y, por lo tanto, aparece más fuerte la idea de voluntad y de decisión.

La densidad semántica «voluntarista» del término «auto-determinación», sobre todo individual, es confirmada en el terreno filosófico y teológico: pensemos, por comodidad, en el mito de Ulises que trata obstinadamente de autodeterminarse, haciéndose mofas hasta de los Dioses, o — especialmente después del cristianismo- en la vana ilusión del hombre-criatura de ser independiente del Dios-Creador, en el titanismo de una auto-determinación (bien expresada por el mito contemporáneo de la exaltación fideísta de la ciencia: el llamado cientificismo), que, sea como sea, ha de rendirse ante los límites ineluctables de la natura-

${ }^{3}$ Para más información sobre este punto, véase mi artículo Dall'indisponibilità (tirannia) alla ragionevolezza (bilanciamento) dei diritti fondamentali. Lo sbocco obbligato: l'individuazione di doveri altrettanto fondamentali, en Politica del diritto, n. 1/2006, 167 ss. y en VV. AA., Il traffico dei diritti insaziabili, L. Antonini (ed.), Soveria Mannelli (CZ) 2007, 129 ss. Sobre la problematicidad, y complejidad, de los derechos (y de una orgánica teoría jurídico-política), cfr. en particular A. Dershowitz, Rights from Wrongs. Una teoria laica dell'origine dei diritti (2004), Torino 2005. 
leza, de la enfermedad, del dolor, de la muerte y, en última instancia, de gran parte de las leyes del universo, que no conoce, ni tampoco domina.

Pero, el alcance del concepto de auto-determinación trasciende las ciencias sociales para reflejarse claramente incluso en las ciencias naturales, en la biología, y especialmente en la citología, donde es posible de alguna manera divisar la sugestión del concepto de auto-determinación ya desde el comienzo de la vida humana, donde, sin embargo, no tiene ningún sentido hablar de «voluntarismo» (si a esta palabra se le atribuye un significado de orientación consciente). De hecho, sabemos que — solo a partir de cierto momento— el embrión se auto-diferencia o auto-determina como sujeto único, por ejemplo distinguiéndose, desde el punto de vista celular, de otro sujeto, igualmente único: el gemelót.

A lo mejor, podríamos incluso considerar la auto-determinación como una species del más amplio genus de la libertad, un ejemplo particular de libertad: más asertiva y auto-referencial, pero siempre referida a una «responsabilidad». Desde un punto de vista estrictamente jurídico-constitucional, en efecto, es difícil imaginar un poder, aunque solo referido a (o sobre) uno mismo que no implique, en todo caso, cierta forma de responsabilidad hacia los demás.

Resumiendo, no queda claro si libertad y auto-determinación son - a causa de la sutiles diferencias de matices psicológicos expuestos- términos solo semejantes, o si, en cambio, podríamos entenderlos como dos verdaderos sinónimos.

Sin embargo, por comodidad de exposición, emplearemos los dos términos filosófico-político-jurídicos recordados como sinónimos y, por mera convención, como tales serán analizados aquí.

\section{LAS DIFERENTES CARAS DE LA AUTO-DETERMINACIÓN EN GENERAL}

a) De los pueblos, bajo la forma de $a_{1}$ ) reivindicación interna (auto-gobierno\} $\mathrm{ya}_{2}$ ) externa (identidad nacional)

Además de la cuestión terminológica citada arriba, cabe subrayar cierta indeterminación en el uso del principio en cuestión que, en realidad, acaba

${ }^{4}$ De hecho, en embriología se habla de una auto-diferenciación, espontánea o independiente, que (contraponiéndose a una diferenciación correlativa o dependiente) se realiza durante el desarrollo del embrión, que - pudiendo engendrar un individuo o una pareja de gemelos o... incluso más sujetos - al principio no tiene siquiera individualidad/unicidad, la cual aparece solo a partir de cierto momento, cuando, precisamente, se auto-diferencia o auto-determina, gracias a la acción de factores intrínsecos de cada célula o de cada esbozo de órgano. Cfr., entre otros, E.G. ConkLIN, Cellular differentiation, en General Cytology (E. Conwdry, [ed.]), Chicago 1924. 
incluyendo fenómenos profundamente distintos entre ellos. Como se ha dicho anteriormente, hay diferentes formas o caras del principio de auto-determinación: en particular, dos colectivas y una individual.

Un pequeño esquema general puede ayudar a entender la articulación del principio de auto-determinación y el desarrollo de este breve estudio.

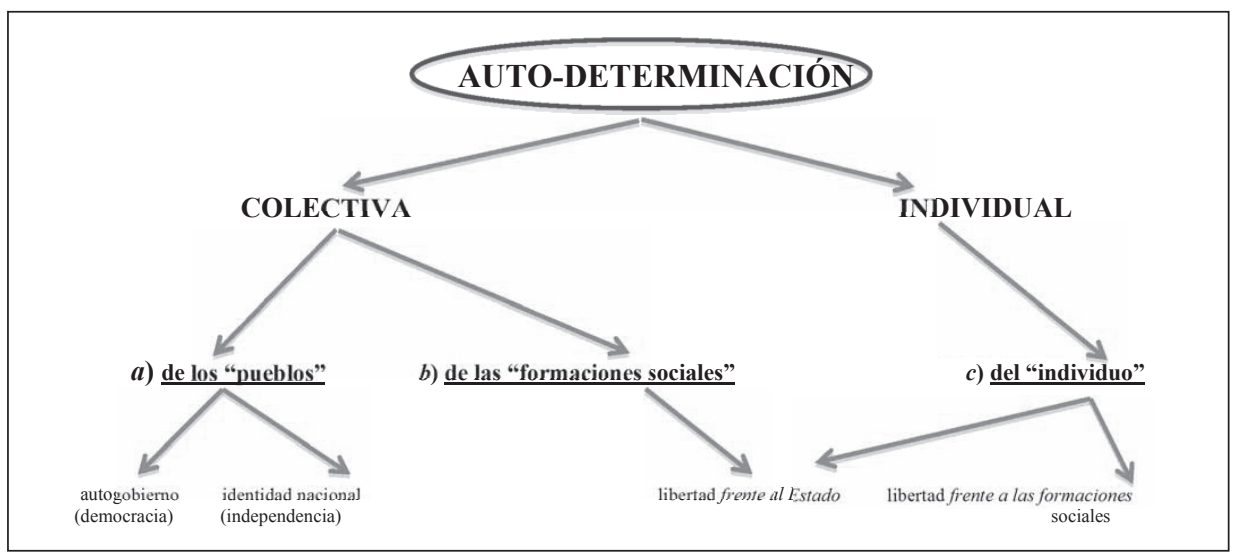

Dejando de lado, por el momento, las formas de auto-determinación «individual» (cfr. §§ 5 y 6), son «colectivas» la auto-determinación de los pueblos y de las formaciones sociales: en ambos casos, podríamos hablar de formas de resistencia contra el Estado.

En el primero - a) auto-determinación de los pueblos - se trata de una resistencia a la opresión que un Estado ejerce sobre una parte de su ciudadanos los cuales, por razones culturales (étnicas, religiosas, lingüísticas, etc.) se sienten, eso es, injustamente, despojados/demediados de su identidad y libertad. Aquí no se habla solo de auto-determinación, sino también de auto-decisión de los pueblos: $a_{1}$ ) interna, como derecho a elegir libremente su propio gobierno, y $a_{2}$ ) externa, como derecho a la independencia nacional. Es evidente, por lo tanto, el diferente alcance y densidad del principio, por un lado como reivindicación ab intra de «democracia», o auto-gobierno, y por otro como afirmación ad extra de una «identidad nacional» ${ }^{5}$.

5 En este segunda y más amplia acepción, el derecho a la auto-determinación de los pueblos, defendido por muchos (de Lenin a Mandela), ha tenido especial relevancia en sentido anti-colonial, a veces en oposición dialéctica con el principio de integridad territorial de los Estados. Cfr.: la Carta del Atlántico (14 de agosto de 1941); la Carta de las Naciones Unidas (26 de junio de 1945; art. 1, parr. 2 y 55); la Declaración sobre la concesión de la independencia a los países y pueblos 
Según quien escribe, las hipótesis que se acaban de presentar son, a lo mejor, las más correctas, desde el punto de vista etimológico, del uso del término autodeterminación.

\section{4. (SIGUE)}

\section{b) De las formaciones sociales: libertad frente al Estado}

En el segundo caso, siempre colectivo - $b$ ) auto-determinación de las formaciones sociales - hay una resistencia, no tanto a la opresión (típica históricamente de los Estados autoritarios/totalitarios), cuanto a la sola injerencia que el Estado manifiesta por la vida «interna» de las llamadas sociedades intermedias «en donde se desarrolla», dice el art. 2 de la Constitución italiana, «la personalità» del individuo ${ }^{6}$. No por casualidad el constituyente italiano (en particular A. Moro) imaginó una sociedad pluralista y articulada, donde el individuo no es una mónada aislada, sino una persona que se relaciona progresivamente según distintos niveles de sociabilidad: desde la familia, hasta el lugar de culto, el sindicato, el partido, las demás asociaciones, etc. ${ }^{7}$ Esta personalidad, naturalmente,

coloniales (1960); el Pacto internacional de derechos civiles y políticos (1966); la Declaración sobre los principios de derecho internacional referentes a las relaciones de amistad y a la cooperación entre los Estados (Onu 1970), etc.

${ }^{6}$ Como es sabido, la fórmula «pieno sviluppo della persona umana»—que en la Constitución italiana figura en el art. 3, II a.- se encuentra también en la Constitución española, cuyo art. 10 habla de «libre desarrollo de la personalidad», aunque lo ponga adecuadamente en relación con los «derechos de los demás». Términos y conceptos análogos se encuentran en otras Constituciones contemporáneas. Por ejemplo, también en la Grundgesetz de la República Federal de Alemania, cuyo art. 2, dice: «Cada uno tiene su derecho al libre desarrollo (Entfaltung) de su propia personalidad», siempre que «no viole los derechos de los demás... etc.». Cfr. P. Rescigno (La persona, autodeterminazione e sviluppo, en VV.AA., Valori e principi del regime repubblicano, 2. Diritti e libertà, S. Labriola (ed.), Roma-Bari 2006, 4 s.), pero luego, analiza el concepto de auto-determinación bajo, en su mayoría, el perfil de la «autonomía privada» o «autonomía negocial de los privados».

7 Eso emerge claramente de los trabajos de la Asamblea Constituyente y en particular de la intervención, precisamente, del diputado A. Moro que, con razón, imaginó una peculiar articulación del texto constitucional: «Si potrebbe dare alla Costituzione un profilo di piramide rovesciata, secondo il criterio della socialità progressiva» (letra cursiva mía), entonces, desde la familia — primera sociedad intermedia — hasta los sindicatos y los partidos, expresión de una sociabilidad «extendida». Véase también E. CHeli, Costituzione e sviluppo delle istituzioni in Italia, Bologna 1978, en particular, 32 ss. Sobre el hecho de que esta propuesta coincidía ampliamente con la impostación/concepción católica de la sociedad —además de los escritos clásicos de U. DE Siervo sobre los constituyentes católicos-cfr., entre otros, P. Pombeni, La Cost ituente, Bologna 1995, pássim. Hay una clara referencia también en G. DossETTI, «Non abbiate paura dello Stato!». Funzioni e 
tiene que ser analizada, siempre y cuando sea posible, en toda su evolución natural: desde el recién nacido hasta el niño, el adulto, el anciano. Nos referimos solo al lapso de tiempo que va desde el nacimiento hasta la muerte porque, desgraciada y emblemáticamente, lo que pasa antes del nacimiento (blastocito, embrión, feto...) y después de la muerte («derecho» del de cuius, respeto hacia el cadáver, culto a los muertos y esperanza religiosa...) — aunque sea de gran importancia para la vida cotidiana de los socios y no completamente ignorado por el derecho- constituye, en términos científicos, un ámbito harto controvertido y, por eso, pasado por alto en los ordenamientos jurídicos. ${ }^{8}$

De todas formas, el reconocimiento de la libertad frente al Estado por parte de las formaciones sociales, u organismos intermedios, es condición indispensa-

ordinamento dello Stato moderno. La relazione del 1951: testo e contesto, E. Balboni (ed.), Milano 2014, pássim, donde muchas veces se repite la idea de una «finalización» de la organización estatal hacia la realización de la persona. Sobre este último concepto, véase en particular F. Pizzolato, Finalismo dello Stato e sistema dei diritti nella Costituzione italiana, Milano 1999.

${ }^{8}$ Es como si dijéramos que, como las dimensiones afectiva y espiritual no son directamente perceptibles por las ciencias naturalistas, no merecen la atención de las ciencias sociales y tampoco del derecho que — angosta pero comprensiblemente- concerniría solo a las relaciones visibles entre los sujetos (tú y tú). Las dificultades emergen aún más ante relaciones místico-religiosas, declaradamente invisibles (tú y Tú), que los ordenamientos constitucionales protegen abstractamente — bajo la forma de libertad religiosa, más que de la auto-determinación (aunque a veces una resulte inseparable del otra) — pero no son capaces de distinguir siempre y nítidamente de formas patológicas, es decir de enajenación psicológica. Es evidente que, debajo de esta difundida (y comprensible) formulación de las ciencias sociales, y especialmente del derecho, hay la dificultad para establecer «qué» hay antes y después de la muerte. Puesto que en este ámbito desconocido (antes y después) no se puede hablar del hombre como persona en sentido estricto, concepto que presupone un mínimo de relacionalidad consciente, personalmente preferimos hablar, incluso en estos casos, de «sujetos» y no, con terminología imprecisa, de un simple «centro de imputación de intereses». Es casi inútil subrayar que también en estas sutiles diferenciaciones se basa, por ejemplo, la distinción entre los términos «derecho subjetivo» y «expectativas». Sobre este último concepto cfr. A. Falzea, Efficacia giuridica, en ID., Voci di teoria generale del diritto, Milano 1978, en particular 302 ss. Del mismo A., véase también sobre la subjetividad, Capacità, en Voci, cit., 87 SS. Sobre la relación entre ciencia y derecho, queremos señalar G. D’Amico, Scienza e diritto nella prospettiva del giudice delle leggi, Messina 2008 y sobre el comienzo y el final de la vida, entre muchos, los dos volúmenes de S. Agosta, Bioetica e Costituzione, Milano 2012. En general, para algunas primeras consideraciones sobre el argumento tratado - y especialmente para una reconstrucción gradualista de las situaciones jurídicas subjetivas, de las que hablaremos más adelante en \$ 9- cfr. A. Spadaro, Cellule staminali e fecondazione assistita: i dubbi di un giurista, en Rass. dir. pubbl. eur., n. 1/2005, 71 ss. Finalmente, profundizaciones y actualizaciones en mi La sentenza Brïstle sugli embrioni: molti pregi e ... altrettanti difetti, en http://www.forumcostituzionale.it (3 de mayo de 2012), y también en Quad. cost. n. 2/2012, 438 ss., en España, como La sentencia Brïstle sobre los embriones: muchos méritos y ... otros tantos defectos, en Revista «Estudios de Deusto», núm. 60, Enero-Junio de 2012, 367 ss. 
ble para que el ordenamiento jurídico se pueda considerar verdaderamente democrático. Eso significa que el Estado da, por así decirlo, un «paso atrás» respecto a las formaciones sociales; o sea, a menudo se limita a «reconocer» las formaciones sociales, por lo menos cuando son preexistentes: pensemos en la Constitución italiana — por no hablar del recordado art. 2- especialmente en los artículos 5 (entes locales), 6 (minorías lingüísticas), 7-8 (confesiones religiosas) y 29 (familia). Como es sabido, en cambio, el Estado autoritario, y aún más el Estado totalitario, no valoran —es más, obstaculizan - el pluralismo de las formaciones sociales, cuya libertad (si se prefiere: auto-determinación) pone peligrosamente en tela de juicio la pretensión de dominio iliberal, invasivo, opresivo del Estado dentro de estos entes intermedios.

En realidad, el reconocimiento del pluralismo y de la libertad de las formaciones «sociales» no es otra cosa que una forma indirecta de reconocimiento de las libertades «individuales». Las formaciones sociales son, de hecho, el primer lugar donde se protege -0 , desgraciadamente, como veremos en $\S 6$ dentro de poco, donde se sofoca- la libertad individual.

Naturalmente, el hecho de que las formaciones sociales estén libres frente al Estado - y por lo tanto puedan establecer reglas «internas» autónomas - no significa que no deban «respetar» al Estado, que por su parte conserva y ejerce su fuerza de forma exclusiva, es decir — como diría Weber- el «monopolio de la violencia legítima». En particular, esa fuerza es desplegada hacia las formaciones sociales anti-jurídicas y/o subversivas: pensemos, dentro del ordenamiento italiano, en las asociaciones ilícitas, las sociedades secretas y terroristas (art. 18 Const.). Con esta última precisión, efectivamente, se puede hablar también de una auto-determinación de las formaciones sociales.

\section{5. (SIGUE)}

c) Del individuo, bajo la forma de $c_{1}$ ) una vez más, libertad frente al Estado. La infinidad de las formas de auto-determinación individual y la relación entre subsidiariedad y auto-determinación. La valoración de la CEDH como «control de razonabilidad de II grado»

El ámbito de ejercicio potencialmente más extendido de las formas de autodeterminación individual es aquél en contra de la organización pública de la sociedad; en otras palabras, en contra del Estado en sentido amplio.

En este caso, el individuo — sea cual sea su status: simplemente hombre/mujer, inscrito/a en las listas de electores de los Municipios de un Estado (ciudadano), 
o de más Estados (doble nacionalidad), y/o titular de situaciones jurídicas activas supernacionales (la llamada nacionalidad dual de la U. E.)— «desea» que los distintos sujetos/organismos colectivos públicos meso- y macro-sociales en que se despliega su personalidad (Estado o Estados, organizaciones super-, trans- o inter-nacionales, o hasta instituciones infra-nacionales, por ejemplo Regiones, pero de todas formas públicas) no invadan su vida, o sea que no atenten contra sus libertades individuales con disposiciones y reglamentaciones que resultarían, a su juicio, opresivas.

Como es fácil entender, se trata de un terreno sin límites, prácticamente inmenso, porque inmensas —es más, inagotables — son las potenciales instancias de libertad de las que el individuo, por tanto cada sujeto, se hace portavoz y de las que se considera, con razón o sin ella, portador. No por casualidad nunca se ha interrumpido la producción de Cartas de las declaraciones de derechos (de la mujer, del niño, del anciano, del prófugo, del embrión, etc. $)^{9}$.

Debido a la natural evolución de la sociedad, que conlleva instancias subjetivas por satisfacer cada vez nuevas e imprevisibles, no es claramente posible realizar una lista definitiva de aquellas que quizás sería mejor llamar, más humilde y concretamente, «pretensiones» de auto-determinación individual. Solo para dar la idea de la abundancia, de la complejidad y del carácter inagotable de esas «instancias» — por ende, es obvio, sin ninguna pretensión de ser completos— se presenta a continuación una primera lista aproximada (nótese: no de imaginación, sino en su mayor parte deducible de la abundantísima jurisprudencia sobre el art. $8 \mathrm{CEDH}$ ), plenamente conscientes de que se trata de un mero florilegio:

- derecho a la vida (no torturas, tratos inhumanos)

- derecho de no nacer $(i ?)$

- discriminaciones (prohibición)

- vida privada

- vida familiar (relación de parentesco y afectividad)

- domicilio (facultad de aislamiento y de visitas)

- espacio privado alrededor de la persona

- inmisiones/contaminación (ruidos, emisiones, olores...)

- residencia

9 Hace ya años habíamos subrayado la imposibilidad de englobar en uno o más catálogos los derechos del hombre, porque expresan inevitables necesidades continuamente in fieri, cfr. Il problema del fondamento dei diritti «fondamentali», en Dir. e soc., n. 3/1991, 453 ss. Sobre la dimensión amplísima, incontenible — cosmopolita e internacional — de todos los derechos humanos, cfr.: A. PISANò, I diritti umani come fenomeno cosmopolita, Internazionalizzazione, regionalizzazione, specificazione, Milano 2011; véase también Diritti deumanizzati. Animali, ambiente, generazioni future, specie umana, Milano 2012. 
- correspondencia y comunicación (paquetes, cartas, teléfono, mensajes de texto (sms), fax, correo electrónico, radio privada en frecuencias no públicas...)

- expresión (expresión del pensamiento)

- intimidad personal (e interpersonal)

- facultad de quedarse «a solas con uno mismo»

- privacidad (que hay que compatibilizar, por ejemplo, con el derecho a informar)

- identidad personal

- nombre y apellido familiar (para la propia persona y para los hijos, eventualmente según el derecho de otro Estado)

- sepultura de los familiares

- imagen (derecho subordinado al carácter público y/o político del sujeto grabado/fotografiado, etc.)

- honor y reputación (protegidos por el art. $8 \mathrm{CEDH}$ en ámbito civil, no penal)

- protección de los datos personales (anagráficos, sobre la infancia, profesionales, de salud, digitales, sonoros, biológicos)

- identidad y relaciones sociales

- vida familiar (heterosexual, homosexual y entre partners que cambian de sexo)

- matrimonio (monogámico, poligámico, transexual)

- filiación legítima, natural, adoptiva (personas no reconocidas, huérfanos)

- relaciones padres/madres e hijos (menores y adultos)

- relaciones patrimoniales, mantenimiento, sucesiones

- residencia del extranjero integrado, con independencia de la ruptura de la unidad familiar

- migrantes (derechos, reunificación y protección de la unidad familiar)

- libre elección de las actividades profesionales/comerciales

- integridad psicofísica (violencia sexual, detención, registro, intervención, etc.)

- conocimiento de los propios orígenes

- reproducción médicamente asistida

- interrupción del embarazo

- sumisión a tratamientos sanitarios

- salud: en particular, consentimiento informado

- eutanasia, suicidio asistido testamento vital, D. A. T.

- actividad e identidad sexual, identificación socio-sexual (gender identification) 
- orientación sexual y transexualidad

- facultad de auto-mutilación

- propiedad privada

- justo proceso

- derecho al olvido (como ausencia/supresión de datos de cualquier tipo sobre la propia persona) y, a la inversa, derecho a ser recordados (herencia digital $)^{10}$

- etc.

Para cada una de las situaciones señaladas —en las que se reconoce, o es reconocible, una intervención negativa, pues una injerencia ilegítima, por parte del Estado (o de otro sujeto análogo) — existe, como es sabido, una jurisprudencia diferente y a veces contrapuesta, tanto $\mathrm{CEDH}$ como nacional, que da lugar a un riquísimo y complejo enredo de la casuística jurídica clásica sobre la cual, si se quiere, es posible hacer una investigación detallada que — sin vacilar en decirlo_- por la amplitud de temas tocados por el principio de auto-determinación, teóricamente puede necesitar hasta «años de investigación»: piénsese solo en los derechos de los ateos, especialmente en relación a la problemática de los símbolos religiosos ${ }^{11}$, o en la auto-determinación del detenido ${ }^{12}$.

Ante la multitud de situaciones jurídicas subjetivas teóricamente relevantes, tratar de hacer un resumen es, pues, por lo menos para quien escribe, imposible.

La complejidad se puede deducir, por ejemplo, del hecho de que lo que en algunas ocasiones es «deber de no injerencia» del Estado en la vida privada, en otras, en cambio, se convierte en «deber de intervención» del Estado en la vida privada. Esa «ambivalencia» une, o mejor, aproxima el principio de auto-determinación al de subsidiariedad, con razón considerado un «Jano bifronte», tanto en sentido vertical como horizontal. De hecho, el principio de subsidiariedad, o bien es expresión de un deber de no injerencia del organismo mayor (o público) con

${ }^{10}$ Cfr., entre otros: M. MezzanotTe, Il diritto all'oblio. Contributo allo studio della privacy storica, Napoli 2009; VV.AA., Il caso del diritto all'oblio, F. Pizzetti (ed.), Torino 2013; T.E. FroSINI, diritto all'oblio e internet, en federalismi.it, n.12/2014(11.6.2014).

11 En este contexto específico — pero se trata de uno de los innumerables ejemplos que se pueden hacer, aunque entre los más controvertidos — es importante el asunto del crucifijo en las aulas escolares: ¿hay o no hay un menoscabo de la auto-determinación individual del ateo? Sobre este punto, entre muchísimos, cfr. L.P. VANONI, Laicità e libertà di educazione. Il crocefisso nelle aule scolastiche in Italia e in Europa, Milano 2013 y, si se quiere, mi La sentenza Lautsi sul Crocefisso: summum jus summa iniuria? (Nota a Corte europea dei diritti dell'uomo. Sentenza 3 novembre 2009, Affaire Lautsi c. Italie, ric. 3014/06), en Dir. pubbl. comp. e comun., I/2010, 198 ss. (pero también en VV.AA., Studi in onore di Angelo Mattioni, Milano 2011, 629-657).

12 Cfr. M. Ruotolo, Diritti dei detenuti e Costituzione, Torino 2002. 
respecto al organismo menor (o privado), o bien, en cambio — precisamente al revés- está considerado, como ya hemos dicho, un deber de intervención/injerencia, por más que solidario, en favor del organismo menor (o del privado). Además, - y esto confirma la existencia de una relación estricta entre los dos principioslo que puede hacer el individuo a solas, auto-determinándose, no tiene que hacerlo el colectivo (público o también formación social privada), que tiene que intervenir/injerirse solo cuando el individuo sea incapaz o carente. La semejanza entre «subsidiariedad»y «auto-determinación» se halla en el hecho de que la intervención subsidiaria siempre cuida los intereses del sujeto débil, cuya auto-determinación no está perjudicada por la acción sustitutiva, mientras que la injerencia del Estado (o del nivel público) es siempre un menoscabo ilegítimo de la libertad del ente menor (o privado).

Además, una lectura correcta, es decir constitucional y no maximalista, del derecho de «auto-determinación individual» quiere precisamente que éste esté acompañado, simétricamente, por la posibilidad de intervención y «limitación» por parte del Estado. Lo difícil es encontrar el equilibrio exacto entre las dos exigencias opuestas.

Junto a la subsidiariedad, obra el principio de proporcionalidad: para ser subsidiaria y no ilegítima (injerencia), la intervención del Estado dirigida a limitar la auto-determinación individual debe ser —además de necesaria y democrática (art. 8.2 CEDH) — «proporcional» a la finalidad perseguida. Pero, en el fondo, la proporcionalidad es solo un aspecto de la razonabilidad, así que, en conclusión, las limitaciones de la auto-determinación son legítimas, y no formas de injerencia, solo si son... razonables (con toda la densidad filosófica y la problemática técnico-jurídica que ese adjetivo conlleva).

Sobre todo, hay que reconocer la necesidad de crear siempre un equilibrio razonable entre los tres grandes grupos de intereses de los que habla el art. 8 CEDH: a) del Estado (seguridad y defensa nacionales, integridad territorial, seguridad pública, orden público, reserva sobre ciertas informaciones); $b$ ) del cuerpo social (bienestar económico del País, prevención de la criminalidad, protección de la moral y de la salud pública); c) de los individuos (libertad, derechos y reputación de terceros) ${ }^{13}$.

13 Esa aceptable tripartición está hecha por C. Pitea - L. Tomasi, Art. 8, en VV.AA., Commentario breve alla Convenzione europea dei diritti dell'uomo, S. Bartole (ed.), P. De Sena e V. Zagrebelsky, Padova 2012, 306. 
$Y$, naturalmente, esa operación de equilibrio produce, cada vez, resultados muy distintos, sobre todo si la legitimidad o ilegitimidad de la (supuesta) «interferencia» $\mathrm{o}$ «injerencia» se basa en los llamados márgenes nacionales de apreciación ${ }^{14}$.

Insisto en señalar que la CEDH no se limita a controlar la exactitud formal y de procedimiento, sino también la proporcionalidad-razonabilidad de la intervención estatal limitativa de la auto-determinación individual. Naturalmente, cuanto más amplio sea el «margen nacional de apreciación», más débil será el control por parte de la CEDH (en este caso será de «no manifiesta irrazonabilidad»). De la misma manera, si la existencia de un «común denominador» en los ordenamientos de los Países miembros de la CEDH — según un criterio que podría ser definido de comparación $n^{15}$ - aumenta el «margen» de valoración de la Corte, muchos otros factores fortalecen, en cambio, el llamado «margen» nacional de apreciación: medidas fiscales, económico-sociales, de protección de la moral, seguridad nacional, incluso en función anti-terrorista, supremo interés del menor, etc.

Con respecto al control de la CEDH, se podría hablar de un control internacional de razonabilidad sobre la... razonabilidad nacional de las limitaciones de la auto-determinación individual. Se trata, en este sentido, de un control de razonabilidad de II nivel o de II grado, tanto más difícil, cuestionable y discrecional cuanto más ambiguo/impreciso sea el marco axiológico proporcionado por la CEDH y cuanto más variada/heterogénea sea la correspondiente jurisprudencia vinculada con las peculiaridades nacionales, más difícil, discrecional y discutible será el control de razonabilidad de II nivel o II grado. Resumiendo - y considerados los recordados tres grandes grupos de interés continuamente en

${ }^{14}$ Sobre este punto, entre muchos, véase F. Donati - P. Milazzo, La dottrina del margine di apprezzamento nella giurisprudenza della Corte Europea dei diritti dell'uomo, y L. OLIVIERI, La dottrina del margine di apprezzamento tra sindacato giurisdizionale e giustizia politica, ambos en VV.AA., La Corte costituzionale e le Corti d'Europa, P. Falzea (ed.) - A. Spadaro - L. Ventura, Torino 2003, respectivamente 65 ss. y 413 ss.; I.A. ANRò, Il margine di apprezzamento nella giurisprudenza della Corte di giustizia dell'Unione europea e della Corte europea dei diritti dell'uomo, en VV.AA., La funzione giurisdizionale nell'ordinamento internazionale e nell'ordinamento comunitario: atti dell'Incontro di studio tra $i$ giovani cultori delle materie internazionalistiche, A. Odennino (ed.), E. Ruozzi, A. Viterbo, F. Costamagna, L. Mola, L. Poli, Napoli 2010, 7 ss.

15 Entre otros, cfr.: VV.AA., Corti nazionali e comparazione giuridica, G.F. Ferrari y A. Gambaro (eds.), Napoli 2006; G. DE VergotTini, Oltre il dialogo tra le Corti. Giudici, diritto straniero, comparazione, Bologna 2010; T. GROPPI, Bottom up globalization? Il ricorso a precedenti stranieri da parte delle Corti costituzionali, en Quad. cost., 1/2011, 199 ss.; C. PINelli, Trapianti, innesti, dialoghi. Modalità di trasmissione e circolazione del diritto straniero, en Riv. trim. dir. pubbl., 2/2011, 495 ss.; G. RePETTO, Argomenti comparativi e diritti fondamentali in Europa. Teorie dell'interpretazione e giurisprudenza souranazionale, Napoli 2011, especialmente 115 ss.; A. LoLLINI, Il diritto straniero nella giurisprudenza costituzionale: metodi «forte» e «debole» a confronto, en Riv. trim. dir. pubbl., 3/2012, 603 ss.; A. Pin, Perché le Corti comparano?, en Dir. pubbl. comp. eur., IV/2012, 1429 ss. 
juego- para la CEDH se podría hablar, en conclusión, de un control de razonabilidad... sobre la razonabilidad, comparado y con equilibrio trilateral (exigencias del Estado, moral pública, instancias individuales).

Sobre este concreto pero difícil terreno — me refiero al análisis de la inmensa casuística ofrecida por la jurisprudencia CEDH (y no solo) sobre la autodeterminación del individuo o, a la inversa, sobre el poder de injerencia del Estado- pienso, sin presunción, que la incertidumbre del derecho es la regla y que la certidumbre del derecho es la excepción. La mencionada inversión entre regla y excepción se percibe menos en los sistemas jurídicos de common law, cuyas sociedades parecen más dispuestas a aceptar soluciones jurisprudenciales distintas «caso por caso» y se percibe, en cambio, en todo su alcance, por así decirlo, subversivo, sobre todo en la tradicional perspectiva de los Países de civil law que tienen la incorregible pretensión de crear un orden sistemático-deductivo (cuando no deontológico-universal) del derecho. En fin, en materia de auto-determinación parece más bien que las diferencias (entre ordenamientos nacionales, jurisprudencias y reglamentaciones supranacionales) son un factor característico o incluso predominante.

En este sentido, el ejemplo quizás más típico en la aplicación práctica del principio de «derecho de auto-determinación» individual es aquello, ya señalado, que permite en España el matrimonio homosexual, mientras que la normación constitucional (que no ha de considerarse como un «poder de injerencia» del Estado) parece descartarlo en Italia, donde, en cambio, está permitida, es más, promovida, una disciplina de las uniones civiles, incluso homosexuales (sent. const. n. 138/2010): se trata, claramente — dado por sentado que hay una común prohibición de discriminación por tendencia sexual, que deriva de la CEDH, pero también del Tratado de Niza- de dos maneras muy distintas de entender la auto-determinación en la materia.

En conclusión, las formales y abstractas pretensiones de universalidad que el principio de auto-determinación contiene en sí mismo, no se pueden satisfacer a través de su simple y general enunciación/proclamación, aunque el término usado - como se señalaba al principio- delata, por lo menos en términos de psicología política, un voluntarismo decisionista, tanto políticamente correcto como quizás soberbio.

La verdad, como se precisará más adelante, es que el significativo espacio dejado a las peculiares tradiciones constitucionales de los Países europeos (el llamado margen nacional de apreciación) procede del hecho de que - como ya se ha mencionado en el § 1- la «macro-ideología» común que llamamos constitucionalismo es «solo parcialmente» una importante base axiológica común. Como veremos más adelante (cfr. § 7), el constitucionalismo no es simple e intrínsecamente pluralista 
y tolerante, sino que — en realidad — tiene por lo menos dos almas muy distintas que inevitablemente originan soluciones práctico-jurídicas diferentes.

\section{6. (SIGUE)}

$\left.c_{2}\right)$ Libertad frente a las mismas formaciones sociales. La auto-determinación individual dentro de las formaciones sociales: sindicatos, partidos, cultos religiosos, familia, etc.

Trataremos, finalmente, el tercer caso de auto-determinación, en el sentido estrictamente individual. Es necesario entenderlo en todo su alcance. Por lo tanto, no solo como forma de resistencia $c_{1}$ ) a la injerencia del Estado, sino incluso como forma de resistencia $\mathrm{c}_{2}$ ) a la injerencia de las mismas formaciones sociales.

Algo sobre los riesgos de injerencia del Estado se ha dicho en el párrafo anterior. Ahora, algunas líneas tienen que ser dedicadas a las hipótesis de injerencia por parte de las mismas formaciones sociales.

De hecho, es verdad, como ya hemos recordado, que el ordenamiento constitucional italiano imagina una sociedad muy pluralista y articulada, donde el papel de los cuerpos intermedios o formaciones sociales es decisivo para el mismo principio de igualdad y según «el pleno desarrollo de la persona» (art. 3, II a.), hasta el punto que incluso por eso — en el caso italiano — se puede hablar de un ordenamiento constitucional liberal-democrático y «personalista».

Sin embargo, precisamente esta relación (entre formación social e individuo) no resulta siempre feliz y tranquila, como es deseable y, en el fondo, desea el constituyente. Desgraciadamente, también las formaciones sociales o cuerpos intermedios —donde, teóricamente, el individuo está protegido de la injerencia por parte del Estado (cfr. § 4)— por el contrario, y prácticamente, en ocasiones puede transformarse, paradójicamente ella misma, en una «jaula», es decir un obstáculo a la libertad (o auto-determinación) en este caso del individuo.

¿Cuántas veces un sindicato, un partido, un culto religioso, una familia, se revelan no lugares de formación y apertura, por ende de libre socialización, sino contextos angostos, oprimentes, sofocantes, en los que el individuo es aplastado?

\section{- Sindicatos y partidos}

Es indudable que la libertad y la auto-determinación individual son a menudo y con fuerza puestos en tela de juicio dentro de organizaciones sindicales y partidos. Pero, efectivamente, los derechos del individuo, y ante todo de las 
minorías, están protegidos esencialmente por la auténtica naturaleza «democrática» - a nivel nacional y local— de estas organizaciones, carácter además exigido por los arts. 39 y 49 de la Constitución italiana. Según nosotros, una intervención limitativa estatal es legítima sobre todo, si no solamente, en este terreno específico (carácter democrático del organismo y de los procedimientos adoptados en él), mientras que es más fácil que sea evaluada como indebida injerencia en los demás casos y por los demás aspectos.

\section{- Cultos religiosos}

En el caso de las formaciones sociales, o cuerpos intermedios, de carácter religioso — los llamados cultos_ es mucho más difícil establecer cuándo la intervención del Estado menoscaba el principio de auto-determinación individual y cuándo, por el contrario, lo protege del carácter iliberal y reaccionario del culto. Nos encontramos en un terreno muy resbaladizo, porque se tocan aspectos delicadísimos que atañen a la libertad de conciencia del individuo. Algunos ejemplos pueden ser indicativos de la dramaticidad existencial, y complejidad jurídica, del tema: ¿pueden los representantes de un culto (presbíteros) hacer propaganda en favor de la abstención desde el púlpito, instando a los feligreses a que no voten en un referéndum abrogativo de una ley del Estado, favoreciendo así la anulación del voto [lo que tuvo lugar en Italia con respecto a la ley n. 40/2004 sobre la reproducción asistida]? Resumiendo: ¿dónde tiene que terminar la auto-determinación de las formaciones sociales, y de sus representantes, con respecto a la reglamentación estatal y dónde empieza, y tiene que ser protegida, en cambio, la auto-determinación del individuo ante las formaciones sociales? ${ }^{16}$ ¿Puede un hijo acusar a su padre por haber sido «subyugado», considerado que, afiliándose a una secta religiosa, cedió todos sus bienes, abandonando a su familia? [resumiendo: ¿el padre, en este caso, tiene derecho a la autodeterminación? ¿Y, si lo tiene, hasta qué punto?]. ¿Puede una madre exigir un examen psiquiátrico para su hija — mayor de edad, rica, joven y linda- que, después de un camino vocacional, decide hacerse monja de clausura, renunciando a todo, creyendo que la chica había sido ilícitamente sugestionada por un cura? [resumiendo: ¿cuándo las medidas de averiguación/control predispuestas por el ordenamiento rebasan los límites de la injerencia frente a la manifestación

16 He tratado el caso — que, en mi opinión, es una forma de injerencia ilegítima de los órganos de la Iglesia católica hacia el Estado italiano: cfr. art. 98 del D.P.R. n. 361 del 1957 en materia de abstensión electoral - en Libertà di coscienza e laicità nello Stato costituzionale (sulle radici «religiose» dello Stato «laico»), Torino 2008, 82 ss. 
de auto-determinación religiosa de la persona?]. De la misma manera, ¿es un motivo legítimo para que una mujer pida el divorcio a su marido cuando este, de repente, haya cambiado completamente su vida tras afiliarse a una secta religiosa, por ejemplo Scientology, originando así efectos negativos sobre su vida conyugal Łresumiendo: ¿dónde termina la auto-determinación (conyugal) de la mujer y empieza la (religiosa) del marido?]. En fin, también estos pocos ejemplos — desgraciadamente reales - confirman que la protección de la libertad individual dentro de estas peculiares formaciones sociales (religiosas) es tan difícil como necesaria, precisamente a causa del carácter muy especial de estos cuerpos intermedios, que teóricamente deberían garantizar, proteger y favorecer la libertad de conciencia, pero que prácticamente pueden en cambio atentar, a veces de forma sinuosa, contra ella. ¿Cómo se puede monitorizar/controlar un dato tan reservado y sensible como la libertad de conciencia? Cabe decir que muchos problemas proceden del hecho de que, en Italia, todavía no tenemos una ley que defina exactamente qué debemos entender por «religión»y «culto religioso», distinguiendo así estos de otros fenómenos y manifestaciones asociativas, como «sectas» y formas varias de superstición. En mi opinión, es en este asunto — definición adecuada del fenómeno religioso: es decir, constitucionalmente compatible_- en el que hay que intervenir.

\section{- Familia}

Por lo que se refiere a la familia, todos los típicos derechos de libertades individuales (derecho de reunión y de asociación, libertad religiosa, rechazo de tratamientos médicos, derechos/deberes de carácter sexual, privacidad, etc.) están protegidos no solo dentro de ella, sino también — nótese — frente a ella. ${ }^{17}$ Es más, podría decirse que la diferencia entre la familia, institución constitucionalmente protegida, y el familismo, degeneración amoral de la familia, ${ }^{18}$ radica esencial-

17 Para una reflexión sobre las principales problemáticas actuales de la familia, entre muchísimos, cfr.: G. Scognamiglio, Famiglia (stato di), en Dig. Disc. pubbl., vol. VI, Torino 1991, 217 ss.; L. Franco, Autonomia della famiglia e identità personale. Tra souranità interna e sussidiarietà performativa europea, Napoli 2012; E. LuCCHINI GuASTALla, Autonomia privata e diritto di famiglia, en Enc. Dir., Ann. VI, Milano 2013, 77 ss. y, ahora, S. SileOni, L'autodeterminazione del minore tra tutela della famiglia e tutela dalla famiglia, en Quad. cost., n. 3/2014, 605 ss. Para un interesante análisis histórico-sociológico de la idea de familia en cinco Países (Rusia/Unión Soviética, Imperio otomano/Turquía, Alemania, Italia, España), cfr. P. GinsBorg, Famiglia Novecento, Torino 2013.

${ }^{18}$ La primera formulación del concepto se debe a E.C. BANField, The Moral Basis of a Backward Society (1958), trad. it. como Le basi morali di una società arretrata, Bologna 1976. Para una aplicación reciente del concepto: A. RaUti - A. Spadaro, Senso dello Stato, familismo amorale $e$ 'ndrangheta: il problema dell'inquinamento criminale della partecipazione politica in Calabria, en http:// 
mente en el hecho de que solo la primera — teóricamente— garantiza, protege y favorece la auto-determinación del individuo, mientras que el segundo aplasta al individuo en una angosta red de relaciones cerradas y/o tribunales que menoscaban la libertad individual, y por tanto, entonces la auto-determinación, de sus miembros: mujer, marido, hijos, otros convivientes (menores o ancianos). Todos estos sujetos, potencialmente, sufren fuertes lesiones de su propia libertad y en particular de su privacidad. Los ejemplos pueden ser muchos también en este caso: si algunas formas de limitación de la auto-determinación de los hijos menores de edad por parte de los padres son legítimas (desde la no concesión de la «paga» semanal hasta la prohibición de salir por razones argumentadas), quedan todavía, en cambio, innumerables formas y maneras de menoscabo de la autodeterminación individual dentro de la formación social familiar: pensemos en el menor de edad homosexual obligado por los padres a negar/rechazar/ocultar su propia actitud/tendencia sexual ${ }^{19}$; en el cónyuge que obliga al otro, en virtud del vínculo de coniugio, a prestar servicios sexuales no deseados o, exactamente al revés, que no cumple con sus deberes conyugales (ambas formas impropias/ilegítimas de auto-determinación) ${ }^{20}$; en la visión del correo electrónico personal o de mensajes sms por parte del cónyuge, o del diario de la hija por parte del padre, o de la vieja correspondencia del abuelo; en la prohibición a salir al anciano constipado; en la presión físico-psicológica de un cónyuge sobre el otro con respecto a sus propias preferencias y amistades (hasta el acoso intra-familiar), etc. Baste con pensar en que las formas de mayor violencia, especialmente contra las mujeres y los niños, se producen todas en casa. El aspecto peor es que estas formas graves de menoscabo de la libertad son a menudo sinuosas, porque paradójicamente están ocultas detrás de mecanismos y relaciones que deberían proteger precisamente a la parte perjudicada. En todas estas situaciones y en muchísimas otras parece que está en juego, de lleno, la libertad (auto-determinación), y solo la concreta jurisprudencia, distinta caso por caso, podrá decirnos cuál es efectivamente la situación real.

En conclusión, cabe hablar de auto-determinación individual incluso dentro de las formaciones sociales, no solo las señaladas aquí, sino todas las demás for-

federalismi.it (n.2 del 26-01-2011), pero también en VV.AA., Vincere la 'ndrangheta, C. La Camera (ed.), Roma 2011, 241-328.

19 Finalmente, sobre este punto, cfr. A. SPERTI, Omosessualità e diritti. I percorsi giurisprudenziali ed il dialogo globale delle Corti costituzionali, Pisa 2013 y F. MANnELla, I «diritti» delle unioni omosessuali. Aspetti problematici e casistica giurisprudenziale, Napoli 2013.

20 Sobre estas y otra problemáticas relacionadas, cfr. más en general —entre otros- P. Veronesi, Il corpo e la Costituzione. Concretezza dei casi e astrattezza della norma, Milano 2007 y U. Breccia - A. Pizzorusso, Atti di disposizione del proprio corpo, R. Romboli (ed.), Pisa 2007. 
maciones, sobre todo si son relevantes a nivel constitucional. Piénsese, además, en la libertad del docente dentro de un colegio o de una universidad connotada religiosamente. El asunto es muy conocido y no hace falta extenderse aquí, pero los casos F. Cordero y L. Lombardi Vallauri en Italia son muy significativos y emblemáticos de su carácter solo parcialmente definido. ${ }^{21}$ Como cabría prever, sobre este terreno será una vez más especialmente la jurisprudencia, y como siempre caso por caso, la que resolverá conflictos delicados y controvertidos.

\section{RELACIÓN NATURALMENTE DIALÉCTICA —Y EN ALGUNOS CASOS TENSIÓN IRREDUCIBLE- ENTRE LAS DOS ALMAS FUNDAMENTALES DEL CONSTITUCIONALISMO CONTEMPORÁNEO: «HETEROCÉNTRICO-ALTRUISTA»E «INDIVIDUALISTA-LIBERTARIA»}

Tal como se ha explicado —y como es sabido— la «macro-ideología» del constitucionalismo engloba más corrientes, más caras, más antropologías. Aquí prestamos atención solo a «dos» de estas corrientes sin, claramente, afirmar que son las únicas, aunque son con razón las más importantes.

En particular, por un lado, una parte importante del constitucionalismo se ocupa precisamente de la afirmación de la libertad — si se prefiere: auto-determinación- del individuo-persona, que se encuentra protegido por esta macroideología, no solo con respecto al Estado, sino también con respecto a cualquier otro sujeto colectivo (familia, asociación, sindicato, partido, Iglesia, etc.)

Por otro lado, junto a la corriente ya mencionada, hay otra y no menos relevante. Se trata de otra cara, otra alma, que no está en contraposición con la de tipo individualista que hemos citado, pero que se orienta — por el contrariohacia el apoyo a los más débiles, si se quiere: a la solidaridad social. Esta doble cara del constitucionalismo surge ya dentro del pensamiento católico, al intentar conjugar —es decir, articular armónicamente- personalismo y comunitarismo, hasta el punto que se habla de "personalismo comunitarista» y «comunitarismo personalista». ${ }^{22}$ Estas dos propuestas de doctrina social, que ya se encontraban

${ }^{21}$ Emblemático el hecho de que — por ejemplo en el caso de Lombardi Vallauri- precisamente la CEDH (sent. del 20 de octubre de 2009) haya juzgado el relativo contencioso judicial viciados por la lesión de los derechos de libertad de expresión (fallo adoptado sin debate ni motivación: art. $10 \mathrm{CEDH}$ ) y de un justo proceso (rechazo a pronunciarse negado por lo jueces administrativos: art. $6 \mathrm{CEDH}$ ).

${ }^{22}$ Cfr. en particular, E. Mounier, Al servizio del personalismo comunitario (París, 1961), trad. it. de A. Lamacchia, Bari 1965. Como es sabido, el pensamiento de este filósofo francés — junto al de J. Maritain — ha influido en parte en los constituyentes católicos italianos de 1946. 
«dentro» del mundo católico, en realidad conviven con dificultad: podríamos hablar de una corriente cristiano-liberal y de una corriente cristiano-social. Según el viento de la historia, en algunas ocasiones predomina la primera, en otras la segunda. ${ }^{23}$

En esta perspectiva, no existe solo una auto-determinación en sentido individual y negativo que coincide, por así decirlo, con un mero non facere del Estado (y, en general, de las organizaciones colectivas). La plena e integral satisfacción del principio de auto-determinación presupone también un facere activo del Estado (o de las organizaciones colectivas) y, en realidad, va más allá del individuo, implicando en su totalidad a las colectividades en una visión más amplia y global, donde el entramado de derechos —en este caso «sociales»- y deberes, igualmente sociales, altera el tradicional concepto de auto-determinación de tipo «individualista» así como es comúnmente entendido en Occidente. La problemática mencionada pertenece a la segunda corriente antes expuesta y no tiene que ser desatendida. ${ }^{24}$

Más en general, simplificando mucho, podríamos sintetizar estas dos corrientes en el clásico binomio libertad-igualdad ${ }^{25}$, pero, en realidad, lo que tratamos de decir aquí es, probablemente, algo más: detrás de las dos almas tradicionales del constitucionalismo contemporáneo (libertad-igualdad), se esconde un enfrentamiento dialéctico muy fuerte entre dos y más amplias y distintas antropologías

${ }^{23}$ La orientación prevaleciente del solio Pontificio, mientras escribimos, está claramente a favor de la línea cristiano-social, con matices declaradamente anti-capitalistas. Cfr. la clara exhortación apostólica de Papa Francisco, Evangelii gaudium, Roma 2013, nn. 53-56, 180-192, 201 206, y pássim. Existe una parte relevante del mundo católico contraria a estas posiciones, que puede ser representada por el estudioso americano, ex consejero del Presidente de los Estados Unidos R. Reagan, M. NovaK, quien recientemente ha atacado de forma explícita al Papa Francisco [además, cfr. su L'etica cattolica e lo spirito del capitalismo, Milano 1994, escrito en la línea de la tradición protestante bien expresada en pasado por M. WEBER en su L'etica protestante e lo spirito del capitalismo (1904-5), Firenze 1970]. Sobre la creciente oposición a la línea de atuación postconciliar, abierta y social, seguida por Papa Francisco — «dentro» de la misma Iglesia católicacfr.: A. Melloni, Il governo di Francesco; M. Ansaldo, Chi e perché rema contro papa Francesco; F. Peloso, Santa Marta, l'anti-curia vaticana; los tres en Limes, 3 de marzo de 2014, respect. 55 ss., 77 ss., 109 ss., pero véase todo el número de la revista (titulado «Le conseguenze di Francesco») dedicado por entero a la difícil renovación empezado por Bergoglio.

${ }^{24}$ Para algunas indicaciones, si se quiere, cfr. mi Dai diritti «individuali» ai doveri «globali». La giustizia distributiva internazionale nell'età della globalizzazione, Soveria Mannelli 2005 (donde figuran ulteriores indicaciones bibliográficas).

${ }_{25}$ Sobre el cual, cfr. en particular las sabias reflexiones de G. SILVESTRI, Dal potere ai principi. Libertà ed uguaglianza nel costituzionalismo contemporaneo, Roma-Bari 2009. 
o Weltanschauungen, que no siempre encuentra un «equilibrio» concretamente adecuado — razonable — en los ordenamientos positivos particulares. ${ }^{26}$

Resumiendo: el verdadero, profundo, áspero enfrentamiento dialéctico es entre auto-centrismo y betero-centrismo.

Estas dos diferentes perspectivas, a las que corresponden por lo menos dos antropologías distintas — que, simplificando por comodidad, podríamos incluso definir liberal y socialista — «coexisten», como dos visiones paralelas, que a su vez presentan otras especificaciones, dentro de la misma macro-ideología a la que llamamos «constitucionalismo».

Los «extremos» principales del enfrentamiento dialéctico que aquí se mencionan son los siguientes:

- auto-centrismo / hetero-centrismo

- tendencia al monismo metodológico/ tendencia al holismo metodológico

- $\quad$ pluralismo (anarquía) / constitucionalismo (jerarquía) ${ }^{27}$

${ }^{26}$ Sobre las significativas dificultades y, al mismo tiempo, la absoluta necesidad de un «equilibrio», por más imperfecto que sea, véase mis textos Bilanciamento, en Enciclopedia filosofica (Bompiani), vol. II, Milano 2006, 1261 s. y Dall'indisponibilità (tirannia) alla ragionevolezza (bilanciamento) dei diritti fondamentali. Lo sbocco obbligato: l'individuazione di doveri altrettanto fondamentali, op. et loc. cit., pero aun antes, en una perspectiva más general, VV.AA., La ragionevolezza nel diritto, M. La Torre y A. Spadaro (eds.), Turín 2002.

${ }^{27}$ La discutible, pero muy indicativa, contraposición es de N. KRISCH, Beyond Constitutionalism. The Pluralist Structure of Postnational Law, Oxford University Press, Oxford, 2010. Que se trate de una dicotomía exasperada y contestable, incluso en las actuales sociedades post-nacionales, es confirmado por la existencia de un constitucionalismo evolutivo de las instituciones europeas [cfr. A. Spadaro, Dalla Costituzione come «atto» (puntuale nel tempo) alla Costituzione come «processo» (storico). Ovvero della continua evoluzione del parametro costituzionale attraverso i giudizi di costituzionalità, en Quad. cost., n.3/1998, 343 ss.; ID., Il caso esemplare della Costituzione Europea come «insieme di atti» (puntuali nel tempo) e «insieme di processi» (storici): dalle C.E.E. (Comunità Economiche Europee), alla C.E. (Comunità Europea), all'U.E. (Unione Europea), agli U.S.E. (Stati Uniti d'Europa), en VV.AA., Verso una Costituzione europea, L. Leuzzi y C. Mirabelli (ed.), Roma 2003, 621 ss.; G. Martinico, Lo spirito polemico del diritto europeo. Studio sulle ambizioni costituzionali dell'Unione, Roma 2011, 27 ss. pero véase pássim\}, y sobre todo por el hecho de que, de todas formas, las Constituciones contemporáneas son pluralistas y, a menudo, son más «procesos históricos» circulares que «actos puntuales» piramidales (cfr. A. SPADARO, L'idea di Costituzione fra letteratura, botanica e geometria. Ovvero: sei diverse concezioni "geometriche» dell' «albero» della Costituzione e un'unica, identica «clausola d'Ulisse», en VV.AA., The Spanish Constitution in the European Constitutionalism context, F. Fernández Segado (ed.), Madrid 2003, 169 ss. y en RBDC, Revista Brasileira de Direito Constitucional, n. 6/2005, 119 ss.), o — si se prefiere- procesos reticulares (entre otros: P. PINNA, La Costituzione e la giustizia costituzionale, Torino 1999, 157, 166 y P. CARrozZA, «Constitutionalism's Post-modern Opening», en M. Loughlin-N. Walker (eds.), The Paradox of Constitutionalism: Constituent Power and Constitutional Form, Oxford University Press, Oxford, 2007, 169). 
- antropología liberal / antropología socialista

- visión cristiano-liberal / visión cristiano-social

- interés individual / interés público

- preocupación por el presente (derechos de los vivos) / preocupación por el futuro (expectativas de las generaciones futuras)

- derechos de los que están cerca (ciudadanos) / derechos de los que están lejos (extranjeros) $)^{28}$

- actitud de quien coloca «el individuo»y su libertad en el centro del ordenamiento / actitud de quien, en cambio, coloca «los demás», con sus exigencias, en el centro del sistema jurídico.

De ello deriva — precisamente dentro de la misma tradición cultural occidental del constitucionalismo - una variedad de planteamientos generales, con múltiples «matices» distintos, según el País considerado y el momento histórico, en que en algunas ocasiones parece predominar el principio de auto-determinación individual (es el caso, por ejemplo, de algunos ordenamientos anglosajones), en otras, en cambio, el principio de solidaridad (es el caso, por ejemplo, de los modelos alemán y, en mi opinión, italiano).

La evidente dificultad para encontrar siempre un equilibrio razonable y adecuado, entre estas dos almas del constitucionalismo encuentra su confirmación en dos factores: a) por un lado, el carácter incierto y fluctuante de la jurisprudencia «internacional», sobre todo de la $\mathrm{CEDH}$, que evidentemente sufre presiones opuestas, pero que al final — cuando puede- deja, al parecer, que el principio de auto-determinación predomine; $b$ ) las dos distintas orientaciones adoptadas, con respecto a múltiples cuestiones, por las magistraturas supremas «nacionales» (en gran parte, las Cortes constitucionales nacionales) que a menudo - probablemente más que los jueces de Estrasburgo_ parece dejar prevalecer las exigencias colectivas de igualdad, entonces, por así decirlo, el principio solidario. Esto, según parece, vale sobre todo para Italia donde, por ejemplo en materia de «derechos sociales», esa diferencia parece bastante evidente. ${ }^{29}$

${ }^{28}$ Sobre estos dos últimos puntos —amor hacia personas lejanas y cercanas, en el espacio y en el tiempo- cfr. A. SPADARO, L'amore dei lontani: universalità e intergenerazionalità dei diritti fondamentali fra ragionevolezza e globalizzazione, en http://www.forumcostituzionale.it/site/images/ stories/pdf/nuovi\%20pdf/Paper/0045_spadaro.pdf, y también en Dir. soc., n. 2/2008, 23 ss. y, con pequeñas modificaciones, en Libertà di coscienza e laicità nello Stato costituzionale (sulle radici «religiose» dello Stato «laico»), cit., en particular 93 ss.

29 Para confirmar esta diferencia, véase por ejemplo la sent. const. n. 264/2012, anotada por A. RUgGeri, La Consulta rimette abilmente a punto la strategia dei suoi rapporti con la Corte EDU e, indossando la maschera della consonanza, cela il volto di un sostanziale, perdurante dissenso nei riguardi della giurisprudenza convenzionale ( «a prima lettura» di Corte cost. n. 264 del 2012), en Consulta onli- 
Ahora bien, frente a la tendencia hacia la koinè de la jurisprudencia internacional, sobre todo europea, en mi opinión, el peligro que casi inadvertidamente se ha corrido en las últimas décadas, y que todavía corremos, es que se atenúe —o peor, que paulatinamente se disipe hasta desaparecer- precisamente esta segunda alma social y solidaria del constitucionalismo, que usualmente, aunque no siempre, es de procedencia cultural latina y por lo general está presente en los países de Civil law. Sobre todo después de la afirmación mundial del mercado y de la globalización, esta corriente del constitucionalismo aparece, en cambio, indispensable para realizar una mayor «justicia social», que —no hay que olvidarlo— es uno de los contenidos axiológicos que enriquecen el constitucionalismo.

Resumiendo: hoy más que nunca, el derecho a la auto-determinación individual no es, ni puede ser, un derecho a la búsqueda de la felicidad en sentido individualista y sin límites, por lo menos si a esta acepción se le atribuye un significado políticamente libertario, económicamente liberal y culturalmente individualista, como en ocasiones «parece» ocurrir en algunos ordenamientos, no solo de Common Law, pero sí en su mayoría W ASP (White, Anglo, Saxon, Protestant), no por casualidad relacionados con una cultura calvinista que valora mucho la libertad y la riqueza individual como signos de benevolencia divina. Obviamente, se trata de fáciles simplificaciones, útiles solo para trazar el perfil de la problemática de la que se está hablando: es muy conocida, por ejemplo, la densidad axiológica de un término-concepto como welfare, que implica, en cambio, recíprocas y complejas implicaciones entre felicidad individual y bienestar colectivo. Es difícil negar también la contextual existencia de corrientes subterráneas que — podríamos decir, como demonios - se esconden a veces detrás de posiciones aparentemente inocuas o modelos teóricos muy generales, puramente culturales.

Insisto: lo que quiero señalar es la relación fuertemente dialéctica —que en algunos casos llega a ser una tensión insanable — entre las dos almas fundamentales del constitucionalismo contemporáneo: «heterocéntrico-altruista»e «individualista-libertaria».

De todas formas, tranquiliza el hecho de que —en los dos modelos generales citados - no debería existir una auto-determinación que pueda coincidir con un

ne (2012), e R. Dikmann, Corte costituzionale e controlimiti al diritto internazionale. Ancora sulle relazioni tra ordinamento costituzionale e Cedu, en Federalismi.it. (15-09-2013). En general, sobre este punto, entre muchos, véase C. SALAZAR, Crisi economica e diritti fondamentali, en Rivista online dell'Aic, 2013, 1 ss.; pero permítanme reenviar a mis artículos I diritti sociali di fronte alla crisi (necessità di un nuovo «modello sociale europeo»: più sobrio, solidale e sostenibile), en Rivista online dell'AIC, n. 4/2011 y La crisi, i diritti sociali e le risposte dell'Europa, en VV.AA., L'Europa di fronte alla crisi. La prospettiva dei costituzionalisti e dei giuslavoristi, B. Caruso y G. Fontana (eds.), (en imprenta, Bologna 2015). 
«derecho a la misantropía» o, lo que es lo mismo, con un «derecho al solipsismo», aunque el solipsismo nos gustara e imaginásemos que nos haría felices. Cuando, con Aristóteles, se recuerda que «el hombre es un animal social» (zõon politikón), no se subraya solo el carácter «relacional» de la condición humana, sino que se sobreentiende — se debe sobreentender- que el hombre no puede ser verdaderamente relacional sin racionalidad, afectividad-empatía y solidaridad; ni, si se quiere, pensando en la tradición laica de la trinidad constitucional francesa, sin fraternidad.

Un terreno —el de la «fraternidad»— que desde luego no ha sido ignorado en el pasado ${ }^{30}$, pero que solo recientemente ha sido adecuadamente reconstruido y estudiado ${ }^{31}$, que debería ser liberado de peligrosas superestructuras postizas (en su mayoría nacionalistas y/o masónicas) y que haría falta, en cambio, volver a descubrir precisamente por su raíz muy antigua, intercultural e interreligiosa, efectivamente fundadora del constitucionalismo universal tout court ${ }^{32}$.

${ }^{30}$ Cómo olvidarse del extraordinario esfuerzo de L. Lombardi Vallauri (Amicizia, carit • diritto. L'esperienza giuridica nella tipologia delle esperienze di rapporto, Milano 1969)? Pero, si se quiere, véase también mis Contributo per una teoria della Costituzione, I, Fra democrazia relativista e assolutismo etico, Milano 1994, en particular 209 s.; L'amore dei lontani: universalità e intergenerazionalità dei diritti fondamentali fra ragionevolezza e globalizzazione, op. et loc. cit., y Costituzione e altruismo, prefazione a La Costituzione della Repubblica Italiana, Mesiano (Vibo Valentia) 2013, 9 ss.

31 Cfr., en particular: F. Viola, La fraternità nel bene comune, en Persona y Derecho, n.49/2003, 141 ss.; VV.AA., La fraternità come principio del diritto pubblico, A. Marzanati y A. Mattioni (eds.), Roma 2007; I. MAssa PINTO, Costituzione e fraternità. Una teoria della fraternità conflittuale: «come se» fossimo fratelli, Napoli 2011; F. Pizzolato, Il principio costituzionale di fraternità. Itinerario di ricerca a partire dalla Costituzione italiana, Roma 2012. Se sañala también, por la reiqueza de datos aportados, la tesis de doctorado de I. VITA, La fraternità come principio giuridico: una prospettiva de iure condito $e$ de iure condendo (Università Cattolica Milano, a.a. 2012-2013). Como es notorio, considera sustancialmente intercambiables «fraternidad»y «solidaridad» G. PECES-BARBA MARTINEZ, Teoria dei diritti fondamentali, Milano 1993, pássim.

32 Es muy atinado, al respecto, el filósofo de la política A.M. BAGGIO, que subraya el cartácter universal de la idea de fraternidad, que se debe recuperar con respecto a aquella, especular, de conflicto: «L'uguaglianza, tra fratelli, consiste nella possibilità di essere, ciascuno, libero nella propria diversità $[. .$.$] Il concetto di fraternità implica dunque una relazione tra libertà (differen-$ za) e uguaglianza (parità) [...] Pensiamo al ruolo di Caino ed Abele nella tradizione biblica, di Seth e Osiride in quella dell'antico Egitto, o quella di Romolo e Remo nella tradizione romana» (Introduzione. La fraternità come categoria politica, en VV.AA., Caino e suoi fratelli. Il fondamento relazionale nella politica e nel diritto, A. M. Baggio (ed.), Roma 2012, 11 s.). Por lo tanto, según el mismo autor, el tríptico francés liberté, égalité, fraternité «ha osato l'inosabile [... avendo trasferito la fraternità... $]$ dall'ambito della famiglia a quello della società $[\ldots$.$] la fraternità è dunque con-$ dizione per la libertà e per l'uguaglianza [...traseferendo... $]$ una condizione di privilegio riservata a pochi in una condizione universale di cittadinanza» (ID., Fraternità o solidarietà? Il ritorno di un dibattito antico, en Nuova Umanità news online, 2012, 202 s.). 
Esta idea positiva y constructiva de «sociabilidad» —que ahonda sus raíces en ese principio de fraternidad que demasiado pronto ha sido olvidado- aparece indispensable incluso para la misma Corte constitucional italiana que, aunque con el lenguaje propio de la jurisprudencia, recuerda que existe «una primigenia vocazione sociale dell'uomo [...] una profonda socialità che caratterizza la persona stessa » [una primigenia vocación social del hombre [...] una profunda sociabilidad que caracteriza a la persona misma] (sent. const. n. 75/1992).

Naturalmente - ya que todo exceso es defecto- igual que la corriente «individualista», también la «solidaria» no debería dar la espalda a su carácter originario, reduciéndose a una mera obligación jurídica, ni pretender absorber o avasallar cada aspecto del constitucionalismo. Si se prefiere: no debería suprimir los demás intereses implicados que, de la misma manera, merecen ser protegidos.

Asistimos, con demasiada frecuencia, en cambio, a peligrosas exasperaciones/ exacerbaciones de los dos componentes tradicionales del constitucionalismo aquí recordadas. De ello derivan «riesgos» especulativos:

a) la acentuación extremista (irrazonable...) de la corriente individualista lleva al peligro del libertarismo constitucional, es decir a la tendencia a suprimir, o gravemente menoscabar, contextuales e ineludibles instancias de solidaridad social, aumentando la primacía de los llamados derechos del sujeto, con la presunción de un «derecho a la búsqueda de la felicidad individual», prácticamente sin límites (se trata de una variante patológica de ideales anárquicos mucho más nobles);

b) la acentuación extremista (irrazonable...) de la corriente solidaria lleva al peligro del paternalismo constitucional, es decir a la tendencia a reprimir, aunque sea por bien pero hasta la opresión, algunas irreprimibles exigencias del individuo, acentuando la primacía de los llamados deberes, con la presunción de que es posible realizar un «felicidad pública», casi un paraíso terrenal (desgraciadamente, en cambio, antecámara — como nos enseña la historia de los totalitarismos- del infierno terrenal $)^{33}$.

Podría quizás afirmarse que el riesgo de paternalismo constitucional es mayor «en los comienzos» de la vida de un Estado democrático, como reacción casi

33 Sobre los conceptos-términos de «paternalismo constitucional» o «paternalismo ético», útiles indicaciones, entre otros, en F. Rimoli, Bioetica. Diritti del nascituro. Diritti delle generazioni future, en VV.AA., I diritti costituzionali, R. Nania e P. Ridola (eds.), vol. II, Torino 2006, 527 ss. y C. PINELli, Principio di laicità, libertà di religione, accezioni di relativismo, en Dir. pubbl., n. 3/2006, 828. Si se quiere, cfr. también mi Libertà di coscienza e laicità nello Stato costituzionale, cit., 101, 221 y pássim. 
natural al régimen opuesto y opresivo anterior, bajo la forma de fuerte limitación de la auto-determinación individual (y colectiva) en sentido político: piénsese en la prohibición de rehacer partidos subversivos o antisistema [el disuelto partido fascista en Italia (XII disposiciones transitorias y finales, Const. 1948)] o en la disciplina del Berufsverbot en la RFA (1949). Sin embargo — prescindiendo del hecho obvio de que contextualmente a los nuevos regímenes constitucionales de la posguerra se ha generado un pluralismo político, antes obstaculizado por regímenes mono-partidistas_- es fácil entender que, de todas formas, se trata de simplificaciones insuficientes. De hecho, todo depende de los distintos «ámbitos» de la auto-determinación: en España, por ejemplo, inmediatamente después de la caída del franquismo y la introducción de la nueva Constitución — si bien con una primera tolerancia política hacia el régimen anterior y sus adeptos- en materia de bioética se ha asistido, como se explicará más adelante, a una especie de explosión de formas de auto-determinación individual que el régimen anterior, en cambio, había coartado durante décadas. En fin, más que nunca en este ámbito, el uso de un método «relacionista» es necesario: pues, todo depende de la perspectiva (histórica y temporal) en que uno se coloca y del ámbito (objeto de investigación) que se analiza. ${ }^{34}$

De todas formas, tanto el libertarismo constitucional como el paternalismo constitucional son dos riesgos que todos los ordenamientos liberal-democráticos y personalistas corren continuamente: en ocasiones es mayor uno, a veces, el otro. $\mathrm{Y}$ ambos —aunque los juristas a veces usen los dos términos como forma de mutua acusación — son, en realidad, «oxímoros jurídicos». De hecho, es precisamente el adjetivo «constitucional» —que implícitamente reenvía a un «sistema de límites»- que contrasta con los dos mencionados «ismos» (libertarismo e paternalismo) con pretensiones absolutistas. En fin, si fueran de verdad «constitucionales», no deberían de ser posibles ni libertarismo ni paternalismo. De hecho, desde el preciso momento en que uno u otro predomina, ya no hay, o de todas formas resulta alterado, precisamente el equilibrio constitucional como «sistema de límites».

El que se trate de una armonía(equilibrio) difícil de mantener con los complejos y controvertidos remedios técnicos predispuestos por el derecho contemporáneo (razonabilidad), se puede deducir del hecho de que los valores en cuestión nunca son afirmados perentoriamente de forma exclusiva o, lo que es lo mismo, anulados in toto. Más bien, son recíprocamente atenuados, así que, mientras uno

34 Para esta propuesta metodológica, distinta de la relativista, se reenvía a mi artículo Ex facto (id est: ex scripto) oritur ratio scientiae iuris (Notarella sul metodo "relazionista» nel diritto costituzionale), en Pol. dir., n. 3/1996, 399 ss. 
crece, de manera especular el otro disminuye, y viceversa, siendo destinados a «convivir». Este equilibrio es el resultado de la utopía que la macro-ideología del constitucionalismo trata de realizar, sin nunca lograrlo plenamente: una especie de felicidad «con los demás», donde los derechos no aplasten los deberes (y viceversa) y, al mismo tiempo, las exigencias de la colectividad pública no opriman a las instancias del individuo (y viceversa). Una mezcla, como es inevitable, intrínsecamente imperfecta, históricamente variable y distinta según los Estados, pero probablemente sin concretas alternativas reales. Fíjense: pese a no ser este el lugar para profundizar el argumento, hay que subrayar el hecho de que la idea de una felicidad "con los demás» no es simplemente un mito religioso (con un firme fundamento teológico) y un principio jurídico tradicional (correspondiente a los deberes constitucionales de solidaridad social), sino un hecho evidente dado por sentado también por la propia filosofía liberal, por la ciencia ${ }^{35}$, además de que por las otras ciencias sociales, especialmente sociología y psicología: en fin, parece consolidado que — para existir — la felicidad tiene que ser compartida... o no existe.

Esta adquisición interdisciplinar e intersubjetiva de las ciencias sociales es quizás mínima, pero de ninguna manera irrelevante. Pese a chocar con las modalidades prácticas de realización concreta de la armonía entre instancias axiológicas en apariencia muy lejanas, al final se confirma ulteriormente en el hecho de que estas instancias, por concordantia oppositorum, resultan intrínsecamente en relación. Efectivamente, y más allá de toda difícil dialéctica, se puede hablar de dos caras de la misma moneda: de hecho, como no se puede «imponer» la libertad, de la misma manera tampoco se puede imponer el altruismo. Para que sea auténtico, también el heterocentrismo tiene que ser «espontáneo», libre, es decir expresión de una auténtica auto-determinación del individuo ${ }^{36}$. Sin embargo, de la misma forma,

35 Desde el punto de vista filosófico — para una reconstrucción de una sociedad auténticamente liberal, de base paradójicamente cristiana, contrapuesta a los modelos utilitaristas e individualistas - cfr. el reciente estudio de L. SIEDENTOP, Inventing the Individual: The Origins of Western Liberalism, Allen Lane, First Harvard University, 2014. Desde el punto de vista biológico, es necesario recordar aquí el descubrimiento de las neuronas espejo (capacidad instantánea y automática de partes del cerebro humano para activarse en términos visceromotores al percibir las emociones de los demás) y los relativos estudios sobre el mecanismo neural de "participación empática» (comportamiento bio-social anterior a la comunicación lingüística). Para esta problemática compleja y controvertida, véase G. RizzolatTi - C. Sinigaglia, So quel che fai, Il cervello che agisce e i neuroni specchio, Milano 2006.

36 No por casualidad de «misura ragionevole di fraternità esigibile» habla F. Pizzolato, $I l$ principio costituzionale di fraternità. Itinerario di ricerca a partire dalla Costituzione italiana, cit., 24, evidentemente preocupado por la «juridificación» del principio. No se puede profundizar aquí en el tema, pero —en mi opinión— es conveniente no mezclar los niveles: el altruismo/heterocen- 
una auto-determinación en sentido individualista exasperado, que no se interesa por las razones y derechos de los demás — sobre todo de los que están lejos en el espacio (no ciudadanos) y en el tiempo (generaciones futuras) — aparece, en su oposición al solidarismo, irresponsable y egoísta. Esta auto-determinación «libertaria», elevándose schmitteanamente, a valor absoluto y tiránico (y paradójicamente disfrazada de defensa de las libertades individuales), resulta incompatible incluso con el simple carácter auténticamente relacional, si no se quiere decir heterocéntrico, del constitucionalismo. Un esquema de síntesis puede ayudar:

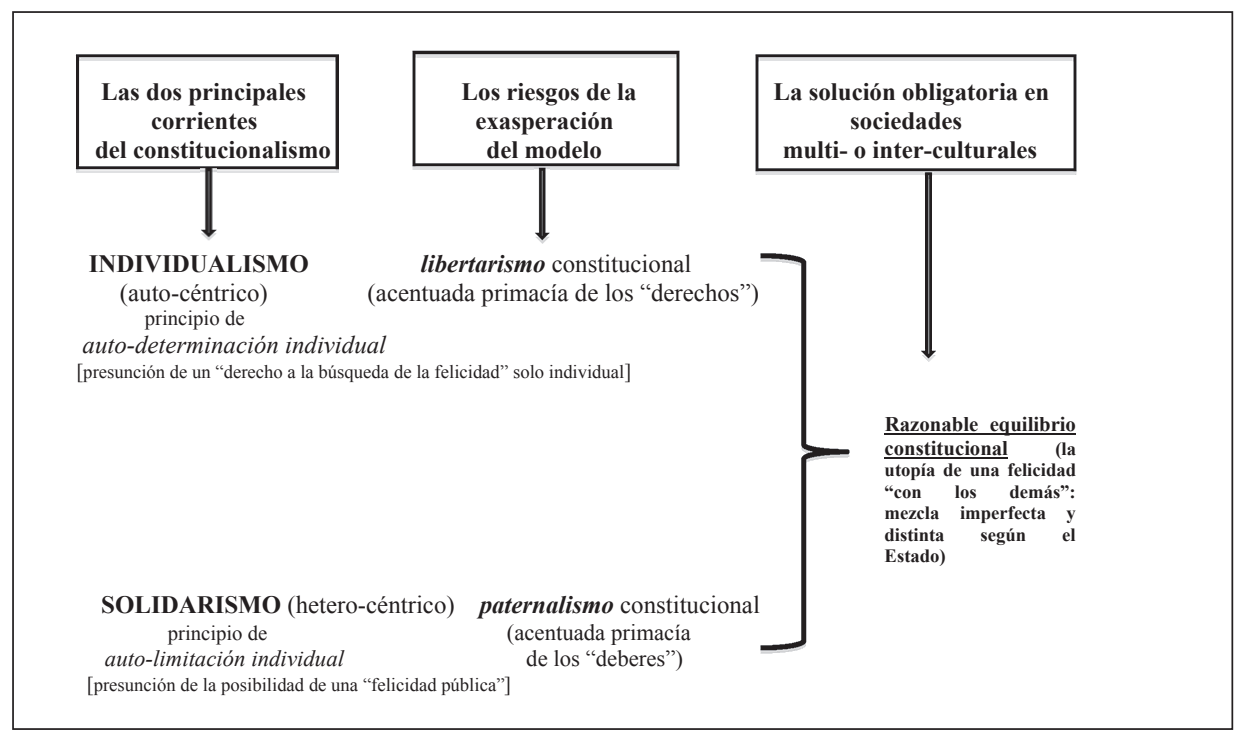

\section{LAS INEVITABLES CONTAMINACIONES ÉTNICO-CULTURALES DE LAS LLAMADAS SOCIEDADES LÍQUIDAS Y LA NECESIDAD DE UN EQUILIBRIO CONSTITUCIONAL, POR MÁS QUE QUEDE IMPERFECTO E IN FIERI. NOTAS COMPARATIVAS ENTRE ITALIA Y ESPAÑA}

Las sociedades contemporáneas, multi-étnicas y multi-culturales — si son analizadas en toda su complejidad - en algunos casos parecen no solo axiológi-

trismo (la «fraternidad hacia alguien») puede ser, es más en mi opinión es, «al mismo tiempo» premisa antropológica y objeto implícito del derecho constitucional, pero precisamente por esta razón, es un concepto que «precede» y va «más allá» del derecho, rozando aspectos y perfiles claramente metajurídicos. 
camente fragmentadas y, por lo tanto, ingobernables, sino también inestables, dispersivas, líquidas ${ }^{37}$. Es evidente que tienen una desesperada necesidad, sobre todo a través del trabajo de equilibrio de las Cortes constitucionales, de encontrar estabilidad a través del «equilibrio» constitucional invocado. Pero ¿cuál es este punto de equilibrio?

Sería ilusorio pensar que el límite general «colectivo» de los intereses públicos y de la moral social pueda, en todo caso, prevalecer sobre el principio «individual» de auto-determinación, aunque tuviéramos una idea prejudicialmente positiva y hasta mítica, de la intervención pública y, por lo tanto, de las limitaciones procedentes de la «ley». ${ }^{38}$ Sin embargo, sería igualmente y extremamente superficial, y en el fondo peligroso, exaltar la libertad - y por tanto el principio de auto-determinación — «individual» como fundamento primero y último de un «sistema» de valores constitucionales mucho más complejo y sofisticado. ${ }^{39}$ Con una metáfora simple, podríamos decir que una verdadera Constitución no puede ser un solo, por virtuoso que sea, de un único músico [libertad de autodeterminación], sino una armoniosa sinfonía musical resultado de las calidades de muchos artistas [más valores: libertad, igualdad, solidaridad, etc.].

37 La expresión, como es sabido, es de Z. BAuman, Communitas. Uguali e diversi nella società liquida, C. Bordoni (ed.), Reggio Emilia 2013.

38 Desde un punto de vista histórico-antropológico, este es el enfoque tradicional, por ejemplo, de la comunidad judía, que siempre ha exaltado, sobre cualquier otra pretensión «individual», el papel y los vínculos de la «ley» por excelencia del pueblo elegido: la Torah. En efecto, un análisis algo más profundo revelaría que incluso una perspectiva como ésta, aunque no se pueda considerar como un mero lugar común, debería someterse a una revisión más atenta. Cfr. al respecto, el interesante ensayo de L. SESTIERI, La Torah: costrizione o libertà?, en ID., Ebraismo e cristianesimo. Percorsi di mutua comprensione, Milano 2000, 25 ss.

39 En el sentido de la primacía exclusiva y fundacional de la libertad, porque la Constitución sería «una ética pública basada en la libertad», se expresa G. ZAGREBELSKY, Intervento, en VV.A., Annuario 2007. Problemi pratici della laicità agli inizi del secolo XXI, Padova 2008, 431. Sin embargo, para un enfoque contrario, cfr. A. Spadaro, Replica, en VV.AA., Annuario 2007, cit., 447 ss.: "può [lo Stato costituzionale] essere fondato solo sulla libertà? Davvero la libertà basta, da sola? E gli altri valori costituzionali: l'eguaglianza, la solidarietà, ecc.? [...] credo che si possa [...] ricordare quello che — pur con tutti i suoi limiti ed eccessi- ha sempre sottolineato C. Schmitt, ovvero che quando un valore fondante pretende di essere uno, ed uno soltanto, allora inevitabilmente finisce col diventare assolutistico, ossia «tirannico» (finendo col cancellare/danneggiare gli altri). È questo, credo, uno dei non molti aspetti della lezione schmittiana su cui tutti possiamo concordare. Insomma, la libertà — presa da sé sola_- diventa inevitabilmente libertarismo. Né è vero che, se la libertà non costituisce l' «unico» valore fondativo della convivenza civile, allora vuol dire che automaticamente si stia evocando al suo posto il principio di autorità: dicendo questo, dimentichiamo che probabilmente alcuni valori superiori si auto-legittimano (come dicono i tedeschi, proprio per i valori costituzionali: selbst-legitimation)». 
En el caso específico de Italia (pero también de Alemania), la naturaleza declaradamente personalista del ordenamiento tiende a excluir que nuestro constitucionalismo pueda en ningún caso reducirse, o acceder, al mero principio de auto-determinación en sentido estrictamente individualista. Dicho de otra manera: sin remarcar en exceso la incidencia del original intent, el peso significativo que los componentes socialistas y católicos tuvieron en la redacción de la Constitución italiana $[y$, análogamente, los constituyentes socialdemocráticos y cristianos, católicos y protestantes, en la RFA] tiende a excluir la posibilidad de que sea posible una interpretación extremista, de tipo meramente libertario, de los derechos individuales. De ello resulta, por lo menos en estos ordenamientos, una concepción cumplidamente «relacional» de los derechos del individuo, entendido, por tanto — como hemos visto- como persona inmersa activamente en la vida de distintas comunidades intermedias.

En cambio, España - pese a ser un País católico y latino: como tal, en abstracto profundamente condicionado por componentes solidarios- eligió darse un ordenamiento distinto, en que el auto-determinación individual parece predominar sobre otros intereses igualmente protegidos por la Constitución. Se trata, probablemente, de una comprensible reacción colectiva a décadas de dictadura franquista y a la consiguiente opresión cultural en la que — guste o no guste- participó, gozando de distintos privilegios, la Iglesia católica española, hasta el punto que ha sido posible hablar, durante este largo período, de fascismo clerical. Además, en España casi no hubo, o tuvo un papel completamente marginal, un catolicismo político «de izquierdas» —que, en cambio, representó una parte significativa de la historia constitucional italiana ${ }^{40}$ - capaz de hacerse portavoz de las instancias solidarias dejadas por completo en manos de la cultura socialista ibérica, por otra parte sensible a los temas de la auto-determinación libertaria. Por estas y otras razones, la actitud prevaleciente de la opinión pública española, después de la caída de Franco y de la instauración de la democracia constitucional, fue la «reacción» contra el pasado y por tanto, una especie de liberación exasperada. ${ }^{41}$ En Italia, desde el 1948 hasta hoy — por mucho que se tienda a subrayar la influyente presencia del Vaticano- las cosas han ido diferentemente: esto, bajo muchos aspectos, ha sido positivo, bajo otros no.

Una rápida comparación entre los dos Países sobre algunos temas, tradicionalmente más candentes para el principio de auto-determinación, pone de manifiesto las diferencias.

${ }^{40}$ Finalmente, véase otra vez G. DosseTtr, «Non abbiate paura dello Stato!». Funzioni e ordinamento dello Stato moderno. La relazione del 1951: testo e contesto, cit., pássim.

${ }^{41}$ Cfr., por ejemplo, P. GInsborg, Famiglia Novecento, cit., pássim. 


\begin{tabular}{|c|c|}
\hline ESPAÑA & ITALIA \\
\hline $\begin{array}{l}\text { Aborto sustancialmente libre (con muy pocas } \\
\text { limitaciones) }\end{array}$ & $\begin{array}{l}\text { Aborto sustancialmente controlado (y el } 70 \% \text { de los } \\
\text { médicos y personal paramédico es objetor) }\end{array}$ \\
\hline $\begin{array}{l}\text { Fecundación asistida homóloga y heteróloga; } \\
\text { embriones supernumerarios utilizables para las } \\
\text { investigaciones hasta el } 14^{\circ} \text { día } a^{42}\end{array}$ & $\begin{array}{l}\text { Fecundación asistida homóloga y, ahora, también } \\
\text { heteróloga; imposibilidad de utilización de los } \\
\text { embriones supernumerarios en la investigación }\end{array}$ \\
\hline Matrimonio homosexual ${ }^{44}$ & Meros proyectos de ley sobre las uniones civiles (Pacs) ${ }^{45}$ \\
\hline Testamento biológico ${ }^{46}$ & Meros proyectos de ley sobre las D. A. T. ${ }^{47}$ \\
\hline
\end{tabular}

${ }^{42}$ La normación española es entre las que más protegen en el mundo la auto-determinación de la mujer, hasta el punto de que se ha decidido que la inseminación artificial será posible incluso pasados los 50 años (pero esta hipótesis se da en ocasiones muy raras). En Italia esto es totalmente imposible y, junto a otros vínculos, favorece el turismo procreativo (véase el caso de la cantante Gianna Nannini, de 55 años). Además en España, desde el 1988, es posible el uso para la investigación de los embriones supernumerarios hasta el $14^{\circ}$ día. He expresado mis dudas sobre la muy distinta disciplina italiana en Cellule staminali e fecondazione assistita: $i$ dubbi di un giurista, cit., 71 ss.

43 Mientras que sobre la fecundación heteróloga la Corte ya se ha expresado favorablemente el 9 de abril de 2014 [sent. n. 162/2014], sobre el tema del uso para las investigaciones de los embriones, hay, mientras escribimos, un recurso ante la Corte constitucional en contra de la ley n. 40/2004: cfr. la ordenanza n. 166 del 7 de diciembre de 2012 emitida por el Tribunal de Florencia en el procedimiento civil promovido por C.S.A. y P.G. en contra del Centro de fecundación asistida «Demetra» S.r.l. y Presidencia del Consejo de ministros, en que se denuncia, además, la violación del derecho al consentimiento informado, a la salud y a la auto-determinación sobre el tratamiento médico. Sobre el tema del consentimiento informado - como derecho autónomo de la prestación médica y referido solo al respeto de la auto-determinación del paciente- véase Cass. Civ. [Tribunal supremo de Casación], sec. III, 11 de diciembre de 2013, sent. n. 27751.

${ }^{44}$ Cfr. R. IBRIDO, L'interpretazione evolutiva e il matrimonio omosessuale. Il caso spagnolo, en Forum online dei Quad. cost. (8 de abril de 2014).

${ }^{45}$ Sobre el tema se reenvía, entre muchos, para la especificidad del caso italiano - que probablemente no permite (quedando la Constitución sin cambios) un matrimonio, sino únicamente «uniones civiles» igualmente protegidas, homosexuales- a A. SPADARO, Matrimonio «fra gay»: mero problema di ermeneutica costituzionale — come tale risolubile dalla Corte, re melius perpensa-o serve una legge di revisione costituzionale?, en www.forumcostituzionale.it (9 de septiembre de 2013) y en www.gruppodipisa.it (septiembre de 2013).

46 Más allá de la ley sobre la «muerte digna» (2010) del Parlamento andaluz, que permite al paciente rechazar un tratamiento que alargue su vida de manera artificial, prohibiendo el ensañamiento terapéutico, en España existe el instituto del testamento biológico, que le permite a los ciudadanos ibéricos — en algunos casos incluso menores de edad- decidir cómo morir, firmando un documento, revocable en cualquier momento, con el que quien firma, mentalmente consciente, declara cuáles son las terapias que quiere (o no quiere) aceptar si se encontrara en condiciones de incapacidad de expresar su propia opinión. Sin embargo, es verdad que — desde el 2002 hasta hoy- solo 150.000 españoles han depositado un testamento biológico, aplicando concretamente la Ley de Autonomía del Paciente. Tampoco se puede ignorar, a veces, cierta peligrosa ambigüedad en las disposiciones normativas españolas. Piénsese, por ejemplo, en el llamado derecho de los catalanes «a vivir con dignidad el proceso de su propia muerte».

47 Una valiosa síntesis de la problemática jurídica italiana sobre este punto es la de C.S. Vigilanti, Le D.A.T. (dichiarazioni anticipate di trattamento) ovvero quando il diritto diventa latitante, en www.forumcostituzionale.it, 2010. 
Partiendo del presupuesto de que hay que respetar las legítimas diferencias entre los dos ordenamientos —expresión de sensibilidades histórico-culturales distintas- se puede afirmar que España es «más avanzada» con respecto al principio de auto-determinación. Si esto en parte es verdad, este principio — como se dirá inmediatamente- en realidad (si no hedonista, desde luego individualista), no parece, por lo menos a quien escribe, precisamente por su unilateralidad, una respuesta suficiente a esa necesidad de equilibrio constitucional antes mencionado.

En particular, pensamos al respecto que la actitud de la sociedad y de los políticos italianos ha sido oscilante: nuestro País, al fin y al cabo, ha resistido bien al proyecto de ley liberticida del centro-derecha que, después del llamado caso Englaro, preveía el tratamiento médico obligatorio generalizado en caso de hidratación y alimentación artificial — tanto que, afortunadamente, nunca ha llegado a ser ley - pero, en cambio, todavía no ha sido capaz de prever uniones civiles, disciplinando jurídicamente las parejas de hecho, homosexuales y no. Desgraciadamente, en general, en Italia, en materia de bioética permanecen muchos prejuicios ideológicos y mucha ignorancia.

Por lo tanto, en mi opinión, Italia podría imitar, por lo menos en parte, a España, con referencia a tres niveles: a) aceptando el uso para las investigaciones científicas de los embriones supernumerarios, congelados y no implantables en el útero, que de otro modo se tirarían a la basura ${ }^{48}$; $b$ ) disciplinando jurídicamente, para evitar discriminaciones especiosas, las uniones de hecho (homosexuales y no), sin por ello acceder automáticamente al matrimonio homosexual (cfr. la recordada sent. const. n. 138/2010); c) normando por fin el llamado testamento biológico.

Por contra, España — que se ha sumido en la posmodernidad con una reacción tranchant, y quizás exagerada al clima opresivo y oscurantista del franquismo- a lo mejor podría dirigir la mirada hacia el modelo italiano, limitando mejor (es decir, con controles más rigurosos) la facultad de interrumpir el embarazo. ${ }^{49}$

${ }^{48}$ Es, como se ha dicho, una idea sobre la que insisto desde hace tiempo (cfr. Cellule staminali e fecondazione assistita: i dubbi di un giurista, op. et loc. cit., y La sentenza Brïstle sugli embrioni: molti pregi e... altrettanti difetti, cit., 438 ss.) y sobre la que esperamos que la Corte ahora, por fin, intervenga según la citada cuestión de legitimidad constitucional que se le ha sometido recientemente.

49 Como es sabido, en España acaba de presentarse, en el momento de escribir estas líneas, un proyecto de ley del Ministro de Justicia Alberto Ruiz-Gallardón («Protección de la Vida del Concebido y de la Mujer Embarazada») de abrogación de la ley orgánica n. 2/2010 de Zapatero («Salud sexual y reproductiva y de la interrupción voluntaria del embarazo»). No obstante algunos puntos cuestionables —o que quizás deberían ser aclarados mejor - de esta normativa (véase en particular el tema de la comprobación de las anomalías fetales), me parece que esencialmente el proyecto de ley «limita»y «controla» más rigurosamente la interrupción del embarazo. Se ha 


\section{CONCLUSIONES: LA NECESIDAD DE UNA «JERARQUÍA» DE LAS SITUACIONES JURÍDICAS SUBJETIVAS. «MÁS ALLÁ» DEL INDIVIDUALISMO VOLUNTARISTA ( AUTO-DETERMINACIÓN»), HACIA EL PERSONALISMO SOLIDARIO ( «LIBERTAD DE CONCIENCIA»)}

La impresión general que tengo es que cada País tiene sus propios tiempos de «maduración» para conseguir el difícil objetivo del equilibrio constitucional entre las opuestas exigencias de garantía de la libertad individual («derecho» a la auto-determinación) y de protección de la moral social («deber» de solidaridad pública). Además, creo que —una vez garantizados los principios fundamentales constitucionales y, en particular, los derechos esenciales de las minorías- es justo respetar las distintas sensibilidades culturales «mayoritarias» en la opinión pública: la democracia funciona así y, por muy duras que sean sus reglas, no podemos aceptarlas solo cuando nos convengan o nos gusten. En fin, la actividad jurídico-constitucional de equilibrio razonable entre las dos exigencias - que exige un trabajo sofisticado y sutil por parte de las Cortes constitucionalesimplica necesariamente que no se fuercen los tiempos de la sensibilización social sobre algunos temas, sobre todo los más delicados y complejos que, en cambio, son a menudo objetos de peligrosas manipulaciones instrumentales e ideológicas, presentes prácticamente en cada ámbito.

Además, quien estudia verdaderamente y seriamente $-\mathrm{y}$ por tanto, libremente- estas problemáticas, raramente adopta una actitud rígida, tranchant, de sustancial intolerancia hacia el punto de vista de los demás, abandonándose a fáciles maximalismos y a la intransigencia.

Emblemático, a este propósito, es el caso del que, a lo mejor, podría considerarse el principal de los derechos de auto-determinación: el derecho a la privacidad. Pues bien, ya es evidente para la gran mayoría que — junto con la clá-

expresado duramente en contra de este proyecto de ley — con significativas argumentaciones (pero quizás con algunos excesos)—S. MANCINI [Spagna: la riforma dell'aborto e le nostalgie patriarcali, en www.forumcostituzionale.it (29 de marzo de 2014)], que habla de «autodeterminazione femminile [...]» y subraya como «non di (bio)etica si discute, ma della pienezza della cittadinanza femminile», puesto que «se il disegno di legge verrà approvato, l'accesso all'aborto non sarà più governato dai tempi, ma dalla ricorrenza di determinate condizioni: che la gravidanza sia l'esito di una violenza sessuale per cui sia stata sporta denuncia (entro la dodicesima settimana) e che sussista un rischio di «menomazioni importanti e durevoli per la salute fisica e psichica della donna o un pericolo importante per la sua vita» (entro la ventiduesima settimana)». 
sica «protección» de la privacidad ${ }^{50}$ — ya es necesario también... «estar protegidos» frente a la privacidad, de la que no se debe abusar. ${ }^{51}$

Es parecido el caso de las normativas que querrían sancionar «opiniones», por ejemplo, que se refieren a la orientación sexual. Establecido que se prohíbe cada tipo de discriminación, no se pueden negar los riesgos y las problemáticas que, sin textos jurídicos bien formulados, podrían generarse por la libertad de la expresión del pensamiento. ${ }^{52}$

Como se puede entender, la cuestión ahora mencionada (delitos de opinión), sobre la que no falta una jurisprudencia constitucional, es muy compleja y delicada, y por lo tanto no está permitido el uso de cómodos atajos consistentes en soluciones superficiales, unívocas y tranchant, como elegir poner siempre un límite a opiniones infames o, exactamente a la inversa, no poner nunca un límite: piénsese, por ejemplo, en el repugnante «negacionismo sobre la Shoah» ${ }^{53}$. En todos estos casos, hace falta reconocer que hay que buscar soluciones de equilibrio razonable, que lamentablemente son, por tanto, a menudo instrínsecamente «imperfectas» [por ejemplo: reconocimiento general de la total libertad de expresión del pensamiento, pero prohibición específica de expresar ideas histórica y científicamente aberrantes en determinados «contextos educativos»].

Es más, quizás sería mejor admitir a priori la insuficiencia del derecho, por lo menos su insuficiencia lógico-procedimental con respecto a exigencias de justicia superiores, y por lo tanto siempre in fieri, destinadas a realizarse solo bajo formas atípicas y/o en plazos de tiempo muy largos. ${ }^{54}$ De hecho, los juristas, y especialmente los constitucionalistas, saben muy bien que, en las situaciones recordadas, si tiramos de una manta demasiado corta para cubrir un lado, la cama queda destapada por otro o, si se prefiere, que a veces es peor el remedio que la enfermedad. Entonces, cabe preguntarse si, para combatir un fenómeno socialmente negativo, es siempre necesario calificarlo en sentido penal como anti-jurídico. Quizás, en algunos casos, otros medios se revelan más eficaces y con menores

50 Véase, entre muchos, por ejemplo: D. Caldirola, Il diritto alla riservatezza, Padova 2006.

51 Cfr. en particular S. SCAGLIARINI, La riservatezza e i suoi limiti. Sul bilanciamento di un diritto preso troppo sul serio, Roma 2013.

52 Me refiero al proyecto de ley llamado Scalfarotto sobre la «homofobia», texto que, en el momento en el que escribo, se está todavía debatiendo y que, por lo tanto, aún puede a ser perfeccionado. Sobre este punto cfr., por ejemplo, C. CARuso (Dignità degli «altri» e spazi di libertà degli "intolleranti». Una rilettura dell'art. 21 Cost., en Quad. cost., n. 4/2013, en particular 810 ss.), que en este sentido, capta muy bien la imposibilidad de una visión unitaria, homogénea y por ende simplista del concepto de dignidad humana.

53 Sobre este tema, finalmente, cfr. S. PARISI, Il negazionismo dell'olocausto e la sconfitta del diritto penale, in Quad. cost., n. 4/2013, 879 ss.

54 No es un caso que F. Carnelutti, en Iustitia, 5/1952, hable de «miseria del derecho». 
«contra-indicaciones». Sobre todo ante los llamados delitos de opinión, parece difícil negar - por lo menos desde una perspectiva estrictamente liberal — la notable labilidad de la frontera entre el Estado constitucional (donde la mera libertad de expresión del pensamiento individual debería encontrar el menor número de límites posibles) y el Estado totalitario (donde, en cambio, se exige, institucionalmente, encauzar el pensamiento individual dentro de un marco de pensamiento colectivo $)^{55}$.

Lo cierto es que, más allá de ciertos límites, los equilibrios son, sí, necesarios y razonables, pero no son expresión — solo porque materialmente «no pueden» serlo- de un equilibrio perfecto, sin daños colaterales. En lenguaje médico se podría decir que algunos medicamentos son necesarios, y por eso deben ser suministrados, pero inevitablemente presentan al mismo tiempo «contraindicaciones» o «efectos adversos», que no se deben pasar por alto, con respecto a los cuales se tendría que adoptar medidas (de control, protección, indemnización, condonación, etc.). Por ejemplo, no cabe duda que, en el caso de delitos de opinión, su sanción lleva en sí misma, más o menos conscientemente, lesiones de otros intereses/derechos constitucionalmente protegidos. De hecho, es evidente que la protección de un derecho dogmática y exasperada, paradójicamente, lleva a la «negación de los derechos en nombre de los derechos» ${ }^{56}$. Y el mismo razonamiento puede hacerse para la gran mayoría de cualquier otra situación jurídica subjetiva, expresión activa de la llamada auto-determinación.

${ }^{55}$ Con base en la diferencia científica entre libertad de pensamiento y libertad de acción, en el pasado he imaginé una distinción correspondiente entre «tolerancia absoluta teórica» (contrariedad en línea de principio a la idea en si de los «delitos de opinión) y «tolerancia relativa práctica» (sancionamiento de «comportamientos» discriminatorios). Cfr. Contributo per una teoria della Costituzione, cit., 261 ss., pero especialmente 286. Esta impostación no es relativista ni hipertolerante, sino que, en realidad, es simplemente ««moderadamente» tolerante» — como afirmé en otro lugar [Ex facto (id est: ex scripto) oritur ratio scientiae iuris (Notarella sul metodo «relazionista» nel diritto costituzionale), cit., 408] — además de en sintonía con el punto de vista de K. Popper [La società aperta e i suoi nemici (London 1945), trad. it., vol. I, Roma 1974, 360], según el cual «se non siamo disposti a difendere una società tollerante contro l'attacco degli intolleranti, allora i tolleranti saranno distrutti e la tolleranza con essi $[\ldots$ noi dovremmo... $]$ proclamare, in nome della tolleranza, il diritto a non tollerare gli intolleranti». [si no nos hallamos preparados para defender una sociedad tolerante contra las tropelías de los intolerantes, el resultado será la destrucción de los tolerantes y, junto con ellos de la tolerancia [...] Debemos reclamar entonces, en nombre de la tolerancia, el derecho de no tolerar a los intolerantes (K. Popper, La sociedad abierta y sus enemigos, trad. española de Eduardo Loedel, Espasa Libros, Madrid, 1957)] Pero, la legitimidad de la reacción contra los intolerantes depende — según quien escribe- esencialmente de los comportamientos (por ejemplo: actos terrorísticos) y no de la explicitación de meras ideas (por más aberrantes que sean).

${ }^{56}$ Cfr. G. Palombella, The Abuse of Rights and the Rule of Law, en Abuse: the Dark Side of Fundamental Rights, The Hague 2006 (ed. A Sajó), 5 ss. 
Las formas de limitación de los «efectos adversos», o perversos que derivan de las manifestaciones más fuertes de auto-determinación «individual» pueden ser muchas; vamos a hipotetizar e indicar al menos 3 de ellas:

\section{Limitación, o repartición, de los efectos temporales de las formas más intensas de auto-determinación}

Ante todo, puede imaginarse que, cuando sea posible, la afirmación del principio de auto-determinación tenga efectos limitados en el tiempo, como en el caso de las acciones positivas con función anti-discriminatoria. Es decir que la medida señalada (definición de un término ad quem de cesación de los efectos) constituye solo una atenuación del daño, pero, como siempre, un correcto equilibrio exige que, ante la necesidad urgente de la afirmación de la situación jurídica subjetiva — que es «individual» pero no debe llegar a ser «individualista»— por lo menos se reduzcan, en el tiempo, los daños sociales. En otros casos, más que interrumpirse, se articulará, a lo largo del tiempo, un efecto jurídico (repartición o escalonamiento): piénsese, sobre todo después de la revisión del art. 81 Const., en la suministración gradual de beneficios financieros o de seguridad social, debidos sin más, pero repartidos en más etapas para evitar peligrosos picos de crecimiento del gasto público.

\section{Jerarquización, o reconocimiento de la diferencia, entre las situaciones jurídicas subjetivas activas}

Puede resultar útil también imaginar una configuración más compleja y sofisticada, y por ende oportunamente "gradualista», de las llamadas situaciones jurídicas subjetivas, que no pueden —ni deben- ser disciplinadas/protegidas todas de la misma forma: de hecho, por ejemplo, no todas las situaciones jurídicas «no sancionadas» son automáticamente derechos, y de la misma manera no todos los «derechos» son, automáticamente, derechos fundamentales. Las formas de autodeterminación o protección —e, igualmente, las formas de intervención «limitativas» de la auto-determinación- pueden, es más, deben ser múltiples, porque son profundamente diferentes las correspondientes situaciones jurídicas. Una de las patologías más frecuentes en el uso distorsionado del concepto de autodeterminación es, precisamente, la de elevar cualquier situación jurídica «no sancionada» a la categoría de «derecho inviolable del hombre». ${ }^{57}$ Aunque sea

57 Por ejemplo, el hecho de que, como es correcto, la interrupción del embarazo — nótese: según las condiciones indicadas por la ley italiana n. 194/1978 — no sea sancionada, no significa, 
perfeccionable y aproximativo (y pido disculpas por ello), se puede por tanto imaginar al menos la siguiente escala jerárquica progresiva de situaciones jurídicas subjetivas: 1) estado de aplicación de una «atenuante» (circunstancia de hecho que permite una reducción de la pena, pero contextualizándola en el cuadro de una situación jurídica pasiva de relevancia penal en la que se encuentra el sujeto); 2) estado de aplicación de una «(circunstancia) eximente» (causa de justificación referida a una situación jurídica que se podría definir casi-activa, porque no permite la no punibilidad del sujeto); 3) «interés legítimo» (situación jurídica activa de la que un sujeto privado goza frente a la administración pública, que a su vez tiene que respetar la ley); 4) mero «derecho» (situación jurídica activa, pero protegida solo a nivel sub-constitucional por parte del ordenamiento jurídico); 5) «derecho constitucionalmente protegido» (situación jurídica activa, expresión de intereses protegidos al máximo nivel jurídico nacional); 6) «derecho reconocido por la Unión Europea» (situación jurídica activa amparada en el Tratado de Niza, para la llamada Pequeña Europa: los 28 Estados de la UE); 7) «derecho reconocido a nivel continental por la $\mathrm{CEDH}$ (situación jurídica activa protegida por la llamada Grande Europa, es decir por la Convención Europea); 8) «derecho inviolable del hombre» situación jurídica activa universal, protegida a nivel global por las convenciones internacionales sobre los derechos humanos). Es evidente, y notorio, que en algunos casos de protección internacional, esta se extiende a los intereses legítimos y no sólo a los derechos. Además, son muchas las diferencias de disciplina y protección entre los distintos niveles indicados. Es más, podríamos irónicamente decir que precisamente estas diferencias, a veces raras, son fructuosas para muchos juristas, especialmente para los de derecho internacional, comunitario y constitucional.

De todas formas, la perspectiva aunque fugazmente tratada aquí, puede ayudar para una mejor calificación, una vez tras otra, del concepto de autodeterminación: de hecho, gracias a esta propuesta «gradualista», una situación jurídica no sancionada (referida a una eximente) claramente no puede considerar-

por lo menos según quien escribe, que la facultad de abortar pueda ser considerada, por eso in en abstracto, igual que un derecho en sentido estricto y especialmente un derecho inviolable (de hecho, el art. 1 de la misma ley dice que «Lo Stato [...] tutela la vita umana dal suo inizio. L'interruzione volontaria della gravidanza, di cui alla presente legge, non è mezzo per il controllo delle nascite»). Esto se torna más cierto cuanto más evidente es que la normativa en cuestión constituye el resultado de un discutido «equilibrio», confirmado por la jurisprudencia constitucional, entre el reconocimiento para la mujer del poder de interrumpir el embarazo — si se trata de la orientación última de su conciencia - y el derecho a la vida del niño: todo esto según las condiciones en cualquier caso impuestas por la ley (riesgo para salud psíquica o física, etc.), también para proteger los demás intereses: por ejemplo, libertad de los operadores sanitarios —objetores de conciencia - de «no» colaborar para esta finalidad. 
se equivalente a una situación jurídica protegida a nivel supranacional (derecho inviolable del hombre). De la misma manera, una situación jurídica protegida a un nivel superior (derecho constitucional), por lo menos teóricamente, debería gozar también de la protección a un nivel inferior (mero derecho sub-constitucional). $\mathrm{Ni}$ se puede excluir una doble o triple protección (por ejemplo: internacional, comunitaria y constitucional), dando por sentado que — en el caso de que haya más formas de protección de un derecho - teóricamente y cuando posible, se debería aplicar la más amplia.

\section{De la auto-determinación hasta la libertad de conciencia}

Finalmente, creo que es necesario hacer un uso más prudente y moderado del mismo término, intrínsecamente voluntarista, cuando no agresivo, de autodeterminación (cfr. $\$ 1$ ). Si, en cambio, se hablara de libertad de conciencia — concepto mucho más profundo y dúctil ${ }^{58}$ — todos (creyentes y no) tendríamos una gran ventaja: «se è vero, infatti, che l'obiettivo finale e supremo dello Stato costituzionale è la realizzazione del principio di dignità della persona umana, e se è vero che ciò è possibile solo a condizione che la coscienza dell'individuo sia libera, francamente non sappiamo se tale obiettivo possa essere definito laico o religioso. È laico, infatti, nella misura in cui la libertà della coscienza può certo prescindere dalle religioni secolari, ma è anche religioso, visto che — per il credente— Dio parla «solo» nella voce della coscienza [...] La libertà della coscienza costituisce, in effetti, l'essenza della "libertà religiosa» e contestualmente l'essenza della «laicità»» ${ }^{59}$. Trabajando sobre el concepto de libertad de conciencia, probablemente encontraremos con más fácilidad soluciones imperfectas, pero «compartidas», para los riesgos de excesos que se refieren al principio de auto-determinación.

58 La referencia a la ductilidad obliga a recordad la propuesta, que por este aspecto se condivide, expresada por da G. ZAGREBELSKY en Il diritto mite. Legge diritti giustizia, Torino 1992.

59 Así me expresé en Libertà di coscienza e laicità nello Stato costituzionale (sulle radici "religiose» dello Stato «laico»), cit., 235 y seguía afirmando: «Dunque, l’accentuazione delle garanzie giuridico-costituzionali in tema di libertà di coscienza è il terreno comune a credenti e non credenti su cui si può costruire un vero Stato laico, laddove laicità e religiosità diventano concetti contigui e in rapporto di mutua integrazione». Sobre este delicado argumento, con matices distintos, véase, entre otros, G. Di Cosimo, Coscienza e Costituzione. I limiti del diritto di fronte ai convincimenti interiori della persona, Milano 2000 y V. TurCHI, I nuovi volti di Antigone. Le obiezioni di coscienza nell'esperienza giuridica contemporanea, Napoli 2009 y D. PARIS, L'obiezione di coscienza. Studio sull'ammissibilità di un'eccezione dal servizio militare alla bioetica, Firenze 2011. 
En conclusión, la lección del constitucionalismo no se reduce simplemente a la lucha por la libertad. Por lo tanto, no podemos detenernos en la mera declamación/celebración, más o menos narcisista, del «yo», en todas sus formas. El derecho constitucional contemporáneo, por su inspiración social, no puede reducirse a un mero «reivindicacionismo subjetivista» (hedonismo cubierto por la auto-determinación). El derecho constitucional no es simplemente una «técnica de las libertades», sino una forma desarrollada y solidaria de la organización social, es un «nosotros».

Eso significa que deberíamos tener el valor de ir «más allá» del principio de auto-determinación (individualismo constitucional), sin el miedo que el llamado bolismo constitucional sea siempre y necesariamente expresión de un paternalismo, más o menos autoritario.

Naturalmente, el ordenamiento constitucional no puede «exigirle» al individuo asociado, por la laicidad que lo caracteriza, que asuma automáticamente «actitudes supererogatorias» de tipo religioso: incluso prescindiendo del hecho de que un vínculo de este tipo («obligación a la donación gratuita») sería una contradictio in adiectu, y por lo tanto un oxímoron jurídico, también ella se revelaría, al final, una forma patológica de opresión totalitaria, y por eso incompatible con el Estado constitucional. Una cosa es el deseo de que el ordenamiento tenga como objetivo la formación de una conciencia cívica elevada y generosa, otra distinta es que de las esperanzas se pase a la obligación jurídica: en realidad, no es aquí en donde se encuentra el derecho de fidelidad a la República. ${ }^{60}$

Pero, es en cualquier caso impensable el constitucionalismo sin «solidaridad», sin «altruismo», sin un intrínseco «hetero-centrismo» de toda la organización social que tienda a proteger al débil, las minorías (y no solo: también los no ciudadanos y las generaciones futuras). No nos referimos, pues, a un general «sentido del Estado», que es posible incluso en regímenes autoritarios y totalitarios, sino a un particular «sentido» de la organización social de tipo solidarista. Y todo esto, guste o no, implica un alto costo en términos de auto-limitación de la libertad individual. ¡Todo lo contrario de la auto-determinación! Quizás, podría decirse, en este sentido, que el constitucionalismo contemporáneo — que sin duda debe aceptar cierta falta de homogeneidad cultural, y también normativa, entre los diferentes Países - es una tentativa de realizar una difícil «mezcla» entre los distintos, es más, opuestos principios de auto-limitación y auto-determinación.

${ }^{60}$ Sobre este punto, recientemente, véase A. MoRELLI, I paradossi della fedeltà alla Repubblica, Milano 2013. 
Afirmamos una vez más que se trata de una «mezcla» inevitablemente imperfecta e inestable, a lo mejor no siempre conflictiva pero para nada irénica y - por más iluminada y caracterizada por valores epocales (y, para algunos, eternos) que ésta sea- desde luego perteneciente al derecho positivo: el resultado de una «costruzione attraverso un confronto il più possibile aperto, dialogico, compromissorio». ${ }^{61}$ Eso se puede deducir de su intrínseca flexibilidad: no solo oscila de Estado a Estado, sino también dentro del propio Estado, hasta de una época a otra. Además, ¿cuántos casos tenemos de evolución, o peor de overruling, en las jurisprudencias de casi todas la Cortes constitucionales, precisamente en materia de auto-determinación? Analizar en los detalles si y cuándo son legítimos —en el sentido de compatibles constitucionalmente o, incluso, constitucionalmente previstos - estos fenómenos de deshomogeneidad y contradictoriedad, incluso intra-ordinamental, no forma parte de los objetivos que nos hemos puesto en este trabajo. Aquí, por el contrario, hemos tratado de evidenciar solo la posibilidad de una lectura dramáticamente ambivalente del principio considerado, según las dos corrientes constitucionales más relevantes.

Dentro del cuadro trazado, me parece que el concepto de libertad de conciencia expresa mejor la idea de un «yo» que intenta convivir armónicamente con un «nosotros». Y pasar del individualismo voluntarista («auto-determinación») a un personalismo solidario («libertad de conciencia») no siempre es una simple operación de «maquillaje lingüístico», sino un factor que debería caracterizar jurídicamente el Estado constitucional. Por lo menos en mi opinión y siempre que aún nos importen «ambas» almas del constitucionalismo cosmopolita contemporáneo. ${ }^{62}$

(traducción de Stefano Morabito)

Title:

The «Two» Approaches of Constitutionalism to the Principle of Selfdetermination

\section{Summary:}

1. Preliminary remarks: from the «abstract» self-determination principle to its «practical» implementations in legal systems. 2. Self-deter-

${ }^{61}$ Así M. Luciani, Unità nazionale e struttura economica. La prospettiva della Costituzione repubblicana, ponencia en el Congreso AIC, 28 de octobre de 2011: véase www.associazionedeicostituzionalisti.it, 78.

${ }^{62}$ Sobre este punto, entre otros, véase en particular Q. CAMERLENGo, Contributo ad una teoria del diritto costituzionale cosmopolitico, Milano, 2007. 
mination or freedom? Equivalent (synonymous) or only similar (related) concepts?. 3. A multifaceted word. Self-determination (in general): a) of peoples, in the form of $a_{1}$ ) internal emancipation [self-government] and $a_{2}$ ) external emancipation [national identity]... 4. (following): b) of social groups: freedom from State's authority... 5. (following): c) of individuals, in the form of $\mathrm{c}_{1}$ ) freedom from State's authority. The limitless forms of individual self-determination and the link between subsidiarity and self-determination. ECtHR judgements as a « $2^{\text {nd }}$ level reasonableness control». 6. (following): $\mathrm{c}_{2}$ ) freedom from social groups' authority. Individual self-determination inside social groups: trade unions, political parties, religious associations, families, etc. 7. The natural dialectic — sometimes the unsolvable conflict - between the two rationales of contemporary constitutionalism: the «unselfish/altruistic» type and the «self-centred/libertarian» one. 8. The unavoidable ethnic and cultural blending process in all the so-called liquid societies and the need for constitutional balance (though always imperfect and in fieri). A brief Italy-Spain comparison. 9. Final remarks: a necessary «hierarchy» of individual legal statuses. «Beyond» voluntaristic individualism («self-determination»), towards solidaristic personalism («freedom of conscience»).

\section{Resumen:}

Los dos principales parámetros o modelos del constitucionalismo contemporáneo son: a) el individualista autocentrista, basado en el principio de «autodeterminación» del individuo (extrema presunción de una felicidad individual) y b) el solidario heterocentrista o altruista, construido con apoyo en el principio de «autolimitación» individual (peligrosa presunción de una felicidad pública). El primero presenta el riesgo de traducirse en «libertarismo» constitucional (exasperación de los derechos), mientras el segundo el de degenerar en "paternalismo» constitucional (exasperación de los deberes). En sociedades multiculturales se impone en cambio una razonable ponderación entre estos dos extremos: una mezcla imperfecta, diversa de Estado a Estado, inspirada en la utopía necesaria de una «felicidad con los otros». Para la consecución de este difícil objetivo, el Derecho constitucional debe intentar proponer una afinada construcción «gradualista» y «progresiva» de las situaciones jurídicas subjetivas activas: desde las situaciones atenuantes y/o no punibles hasta el derecho inviolable universal.

\section{Abstract:}

The two main patterns of contemporary constitutionalism are: a) self-centred individualism, based on the principle of individual «self- 
determination» (extreme belief in private happiness) and $b$ ) solidaristic altruism, grounded on the principle of individual «self-restraint» (dangerous belief in public happiness). The former bears the risk of constitutional «libertarianism» (polarizing the rights), the latter could lead to constitutional «paternalism» (polarizing the duties). On the contrary, multicultural societies need reasonable balancing between these extremes: an imperfect mix, varying from State to State, inspired by the necessary utopia of «happiness with others». To this end, constitutional theory is asked to attempt a refined «graduated» and «progressive» scheme of individual legal statuses: from extenuating and/or non-punishable status to universal fundamental right.

Palabras clave:

Autodeterminación, constitucionalismo, libertad, conciencia, individualismo libertario autocentrista, personalismo solidario beterocentrista.

Keywords:

self-determination, constitutionalism, freedom, coscience, self-centred libertarian individualism, altruistic solidaristic personalism. 